\title{
Article \\ Design of an Anti-Slip Mechanism for Wheels of Step Climbing Robots
}

\author{
Nayan Jyoti Baishya ${ }^{1, *,+(\mathbb{D}, \text { Bishakh Bhattacharya }}{ }^{2,+} \mathbb{C}$, Harutoshi Ogai ${ }^{1, *,+}$ and Kohei Tatsumi ${ }^{1,+}$ \\ 1 Graduate School of Information, Production and Systems (IPS), Waseda University, Production Engineering, \\ 2-7 Hibikino, Fukuoka 808-0135, Japan; tatsumi.kohei@waseda.jp \\ 2 Indian Institute of Technology Kanpur, Mechanical Engineering, Kalyanpur 208016, Uttar Pradesh, India; \\ bishakh@iitk.ac.in \\ * Correspondence: nayanb@fuji.waseda.jp (N.J.B.); ogai@waseda.jp (H.O.) \\ + These authors contributed equally to this work.
}

check for updates

Citation: Baishya, N.J.; Bhattacharya, B.; Ogai, H.; Tatsumi, K. Design of an Anti-Slip Mechanism for Wheels of Step Climbing Robots. Actuators 2021, 10, 259. https://doi.org/ $10.3390 /$ act 10100259

Academic Editor: Micky

Rakotondrabe

Received: 19 August 2021

Accepted: 26 September 2021

Published: 30 September 2021

Publisher's Note: MDPI stays neutral with regard to jurisdictional claims in published maps and institutional affiliations.

Copyright: (c) 2021 by the authors. Licensee MDPI, Basel, Switzerland. This article is an open access article distributed under the terms and conditions of the Creative Commons Attribution (CC BY) license (https:// creativecommons.org/licenses/by/ $4.0 /)$.

\begin{abstract}
This manuscript presents a shape memory alloy (SMA) actuated anti-slip mechanism for the wheels of step climbing robots. The proposed mechanism comprises three kinematic chains considering the Lazy Tong and the bi-stable four-bar mechanism. Chain 1 of the mechanism is used to clamp on the edges of the stairs to avoid slipping. The second chain of the mechanism is used to switch the mechanism between two stable positions, i.e., open position and closed position, of chain 1 . For activating the mechanism, the third chain is employed which is based on SMA wire. Furthermore, the mechanism is designed to achieve passive switching from the open position to the closed position. Equations are developed to determine the dimensions of various members. Using those parameters, a 3D model of the proposed mechanism is developed. Stress analysis is performed and the model is found to be safe under a load of $250 \mathrm{~N}$ with a factor of safety of 3.025. The mechanism is attached to either side of a wheel of the outer radius of $290 \mathrm{~mm}$. To analyze the kinematics of the mechanism, a three-dimensional model in MSC Adams is developed and studied. The force required by SMA actuator is found to be less than $5 \mathrm{~N}$. The proposed mechanism may be used for various unmanned robotic systems while mitigating step-like obstacles in the path.
\end{abstract}

Keywords: mechanism; assistive technologies; actuators; smart materials; bi-stable mechanism; step-climbing robot; four-bar mechanism

\section{Introduction}

Rapid developments in the field of robotics and automation have led to the use of robots along with humans for performing complex tasks. This has improved the accuracy and efficiency in preforming various tasks. In some of the fields like surveillance, exploration, and rescue in dangerous locations (e.g., nuclear or fire disasters), robots are deployed instead of human rescuers. This significantly reduces the risk of the adverse effect on human rescuers, which may have been caused by the hazardous environments of the rescue location. In such rescue robots, one of the key features is to overcome obstacles or to be able to maneuver over steps of stairs.

Many researchers have been working rigorously and successfully in developing robots which can climb up/down the stairs. Such robots may be widely classified in three groups i.e., tracked, articulated leg, and hybrid system. Robots using a track belt as a driving mechanism are known as a track-based stair climbing robot [1-3]. Although tracked based systems are successful in climbing up/down the stairs, these robots are slower on the plane surface as compared to wheeled robots. In addition, some researchers have developed systems based on articulated legs [4]. The biped robot legs are based on the Stewart Platform. Each leg of the robot is controlled by six linear actuators. These actuators are connected to the waist of the robot by six universal joints (degree of freedom (DOF) of universal joint is 2). The actuators are connected to the foot by three spherical joints (DOF 
=3). Complex control design algorithms are used to actuate twelve actuators to maneuver such robots. These robots can overcome obstacles efficiently; however, complexity in design and control result in an increase in the development cost of such robots. In addition, the operating speed of such robots is slow in planes. Hence, to overcome such problems of robots on a plane and achieve step climbing, researchers have worked towards the development of hybrid systems. Such hybrid systems may be further categorized into two groups i.e., wheels with track and wheels along with articulated legs [5-16]. These hybrid robots are equipped with two systems, one for maneuvering on a plane surface and the other for overcoming obstacles. Depending upon the situation, either one of the two systems is activated. Researchers have worked on modular-based stair climbing robots[17]. In such robots, detachable modules are attached to the parent robots depending on the situation. Linear actuators are used in such modules to push the robot upward on the stairs. These robots require the presence of an operator for connecting the modules at the time of operation. Robots based on power linkage are developed to achieve step climbing [18,19]. In this system, clusters of wheels are added along with powered links. Wheel clusters are used to overcome obstacles, whereas powered links are used to push the system forward on the stairs.

An interesting hybrid mechanism based on the sliders is discussed in a series of articles [20-24]. Clamping mechanisms are used to clamp on the edge of steps and, with the help of sliders, the robot pushes itself forward on the steps. Some of the developed stair climbing robots are based on wheel clusters [25-34]. These wheel clusters usually consist of two or three wheels. To overcome stairs, these clusters of wheels rotate about its center/centroid of the line/triangle joining center to the wheels. Some researchers used rotating multi-limb structure to maneuver the robot on stairs [35,36]. Another research work based on the slider-crank mechanism is developed [37-39]. In this robot, manipulating the center distance between the front and rear wheels by means of a slider-crank mechanism, step climbing is achieved. We may notice that the track-based and articulated step climbing robots are relatively slower on the in-plane surface, whereas in hybrid robots, due to use of two different mechanisms for plane motion and stair climbing, the weight and control complexity increase. Hence, among all the methods discussed, wheel based systems are better in terms of speed and simplicity of control while maneuvering on the plane as well as stairs. However, in the wheel based system, the successful operation of the system to climb up or down the stairs depends entirely on the friction between the wheel and the surface of stairs. If the friction between the wheel and surface of the stair is significantly low, the risk of slipping while climbing of the stairs is inevitable. Hence, a mechanism that can clamp on the edges of the stairs while climbing up or down is necessary to eliminate the dependency of the step climbing robot on the friction between stair surface and the wheels to maneuver on stairs.

In this article, we have proposed an array of SMA based clamping system attached to the wheels for step climbing. Clamping on the edges of steps will eliminate the possibility of the slipping of wheels on steps during climbing up or down the stairs. The proposed anti-slip wheel mechanism is comprised of three kinematic chains. These three chains act in conjunction to achieve successful clamping on stairs during climbing up or down the stairs. Each of the chains has a specific role in the proposed mechanism. Chain 1, also called the clamping mechanism, is responsible for clamping on the edge of the stairs. This chain has two operating positions, i.e., open position and closed position. The open position is activated during the motion of the climbing robot on the stairs. On the planar surface, the chain remains in a closed position. The shift between the closed position to the open position is achieved by an actuator mechanism, whereas the transition between the closed position to open position is achieved passively. Chain 2 of the mechanism is based on a bi-stable four-bar mechanism [40]. The two stable states of this chain help the kinematic chain 1 to be in either the open position or the closed position. In addition, this helps in reducing the length of actuation of the actuator by half. The third chain, Chain 3 (actuator mechanism), is based on a Lazy-Tong mechanism [41] and actuated by a SMA 
based actuator. SMA based actuators are simple, lightweight, and power-efficient. Hence, SMA based actuators are chosen for actuation of the proposed anti-slip wheel mechanism. Kalra et al. have elaborately discussed the formulation of SMA wire based on a 1D Brinson model [42].

This paper is organized as follows: Section 2 explains about the design approach and the working principle; in Section 3, designing and modeling of the mechanism is discussed. Section 4 illustrates the results of the simulations. Section 5 concludes the paper.

\section{Working Principle and Design Approach}

In this section, the working principle and the design approach to select the proposed mechanism configuration of the proposed mechanism is explained.

\subsection{Working Principle}

Figure 1 shows the positions of the anti-slip mechanism during plane motion. It may be noticed that the proposed mechanism has two stable positions. These two positions are called the open position and closed position. The mechanism will remain in a closed position during plane motion as shown in Figure 1. While climbing up or down the stairs, the open position is activated using an SMA actuator, as shown in Figure 2a,b, respectively. While climbing up or down, the mechanism will clamp on the edges of the stairs to avoid any slipping of the wheels. This will result in improvement in the efficiency and safety of the climbing robot.

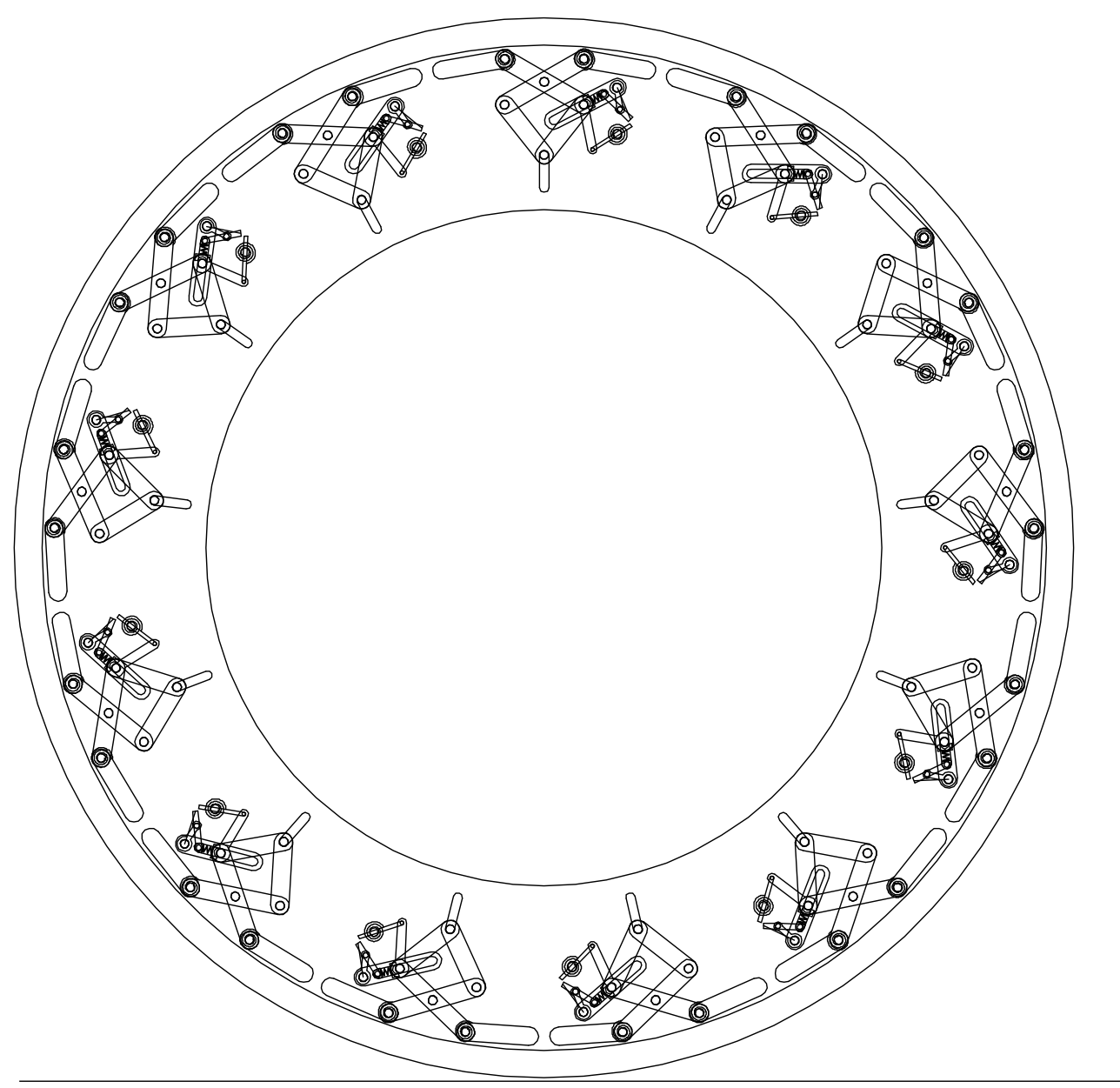

Figure 1. Working principle of an anti-slip mechanism on the plane surface. 


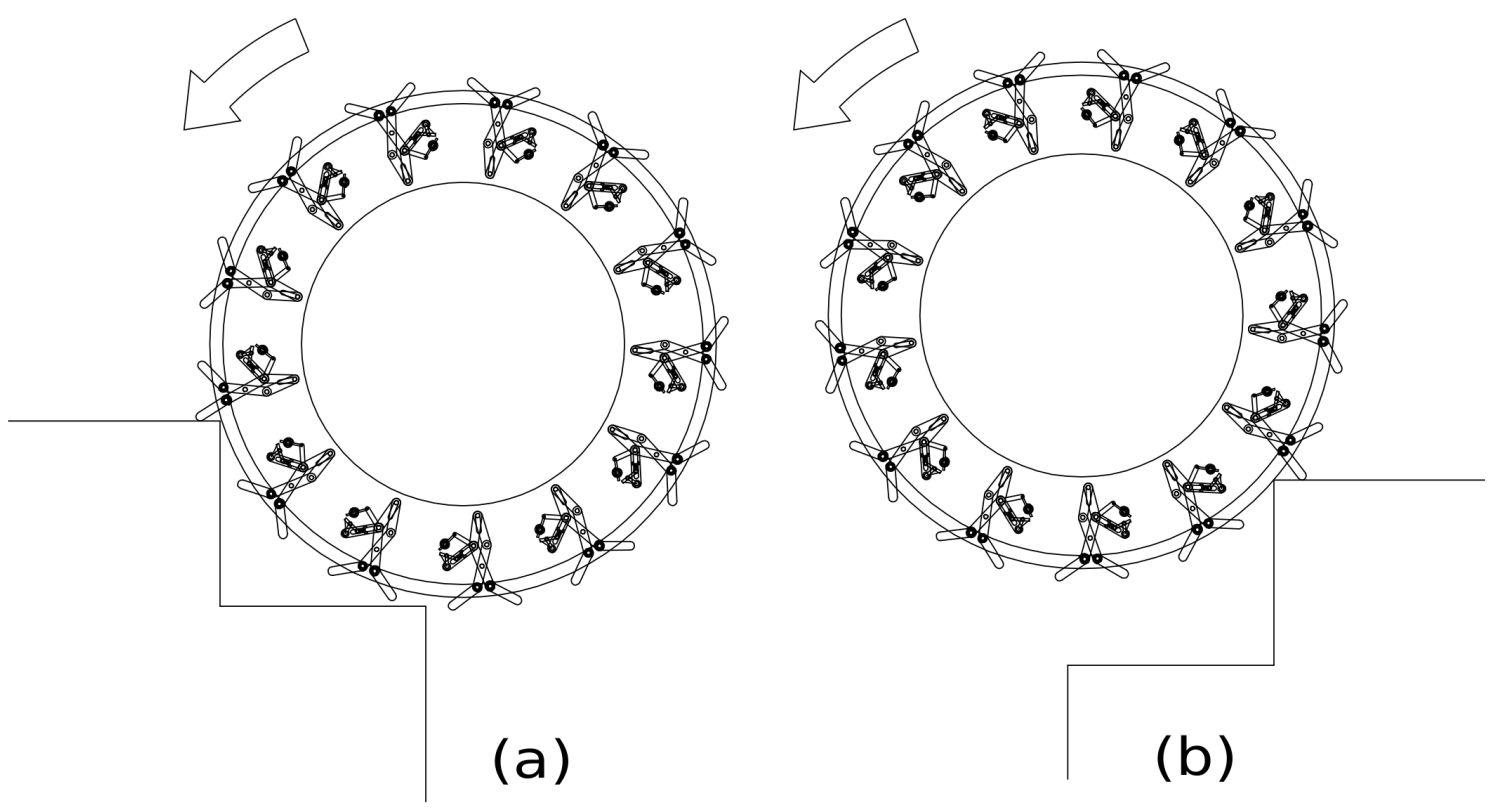

Figure 2. Working principle of an anti-slip mechanism (a) while climbing on stairs; (b) while climbing down stairs.

In Figure 3a, a detailed view of the proposed mechanism is shown. The mechanism consists of three sets of kinematic chains, chains 1, 2, and 3, represented in green, red, and black colors, respectively. Encircled numbers attached to the links are used to denote different links and, throughout the article, these numbers are used to refer the links. Chains 1 and 3 are based on a Lazy Tong mechanism, and chain 2 is based on a bi-stable four-bar mechanism. Switching from the closed to the open position of the mechanism is done by passing a current through SMA wire, which increases the temperature of the wire because of joule heating. This results in shrinkage of SMA wire which in turn pushes the joint $P_{3}$. Joint $P_{3}$ is a common joint of both chains 1 and 2 and connects link 1 and 4 . In addition, the dotted red line on link 1 represents the shared part of the link by both chains 1 and 2. The bi-stable nature of the chain 2 is achieved by using torsion spring 2 , which forces the joint $P_{3}$ to remain in either of the two extreme positions. The two extreme positions of the mechanism are limited by the slot $L_{S 1}$ in chain 1 (shown in green). The torsion springs in chain 1 are responsible for aligning of link 2 with link 1 when the mechanism clamps on the edges of steps. Alignment of links results in maintaining the open position of the mechanism throughout the entire rolling of the wheel on steps.

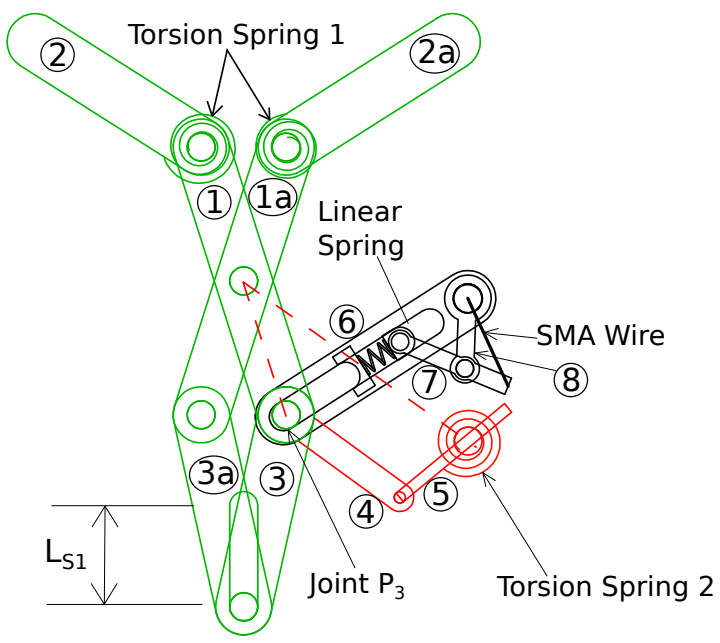

(a)

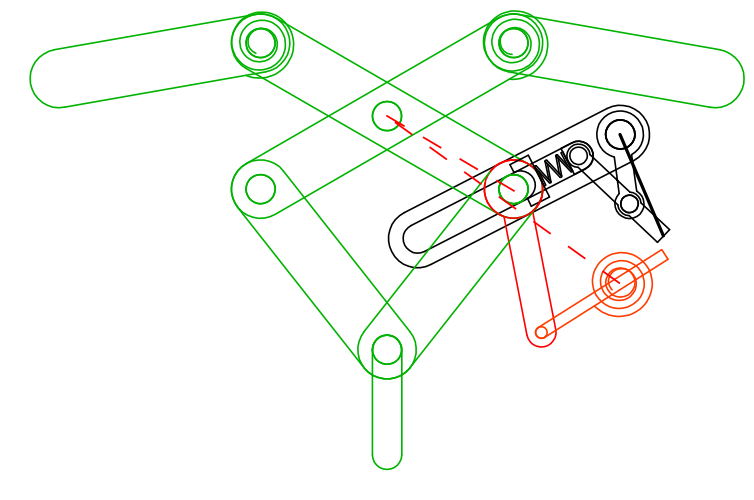

(b)

Figure 3. Detailed front view of the anti-slip mechanism (a) open position; (b) closed position. 
Figure $3 \mathrm{~b}$ shows the closed position of the proposed mechanism. Switching from the open to the closed position is achieved by the push generated by contact force between link 2 and the horizontal ground. Once all of the climbing up or down the stairs is completed, the supply of current to the SMA wire is stopped. This will result in a decrease in the temperature of the SMA wire, and the actuator will return to the elongated state. This will allow the joint $P_{3}$ to retract to the the closed position of the mechanism when joint $P_{3}$ is pushed by the contact force between link 2 and the ground. However, while climbing up or down stairs, the current will continue to flow through the SMA wire. Hence, even if, due to any contact force between link 2 and the ground, the joint $P_{3}$ retracts, the linear spring will push joint $P_{3}$ back to the open position once the contact force disappears. This will allow the mechanism to be ready for clamping on upcoming steps.

\subsection{Design Approach}

In the previous section, working principle of the proposed mechanism is explained. In this section, the design approach to decide the configuration of the mechanism is illustrated. It may be observed from Figure 3 that link 2 and 2(a) of Chain 1 are used to clamp on the edges of a stair while climbing up and down the stairs, respectively. Use of a lazy tong mechanism to operate these two links helps to open the links with a single actuator instead of using one actuator each for link 2 and 2(a). Hence, this reduces the number of actuators. Using a bi-stable four bar mechanism in chain 2 helps in isolating the clamping mechanism from the actuating mechanism in the open position of the mechanism. Moreover, it helps in reducing the actuation length of the SMA actuator. The mechanism of chain 3 is used to utilize the property of an SMA actuator which shrinks when heat is applied to the actuator.

\section{Design and Modeling}

This section illustrates the design approach for the effective working of the anti-slip mechanism. Figure 4 represents a schematic of the proposed mechanism. Link numbers may be referred from Figure 3 (encircled numbers). The three chains of the proposed mechanism act in conjunction to successfully clamp on the edges of the stairs. Design approaches to determine the dimension of various members of the mechanism are explained in the following sections.

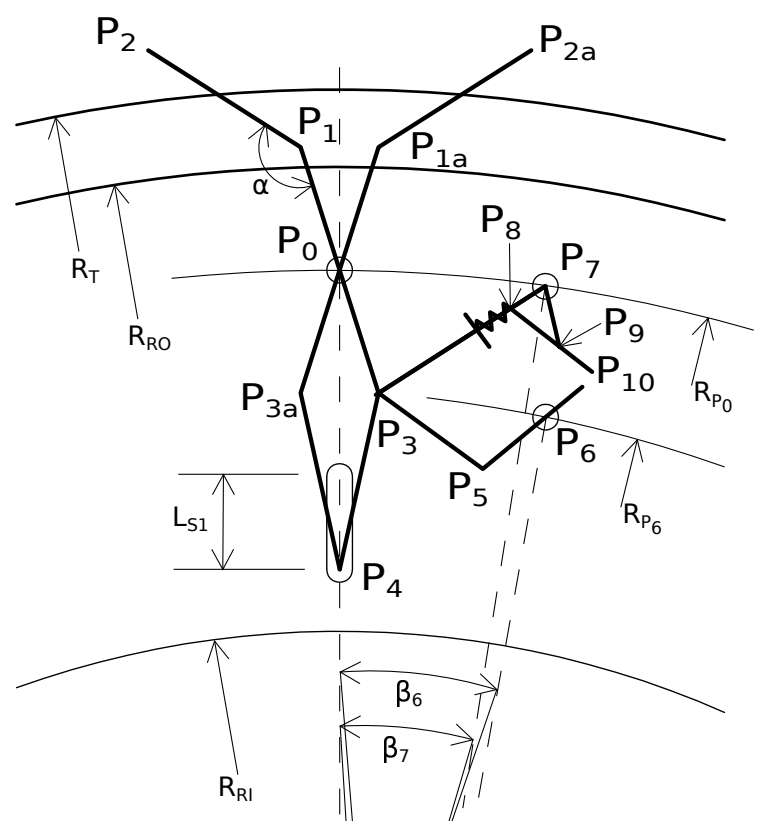

Figure 4. Schematic view of the anti-slip mechanism. 


\subsection{Chain 1: Clamping Mechanism}

The clamping mechanism (Chain 1) consists of two symmetric parts. One part is used while climbing up the stairs and the second part is used while climbing down the stairs. Since only one of the two symmetric parts will be active while either climbing up or climbing down the stairs, both parts are combined in one mechanism and actuated by a single actuator. This reduces the number of actuators to operate the system for ascending and descending cases.

Figure 5a illustrates a situation where the wheel is moving in a horizontal plane and the mechanism is in the open position. Link 2 has just touched the horizontal plane. Figure $5 \mathrm{~b}$ shows a scaled-up view of the tip of link 2 , when it touches the horizontal plane. Angle made by point $P_{2}$ with vertical, $\beta_{2}$, is given by:
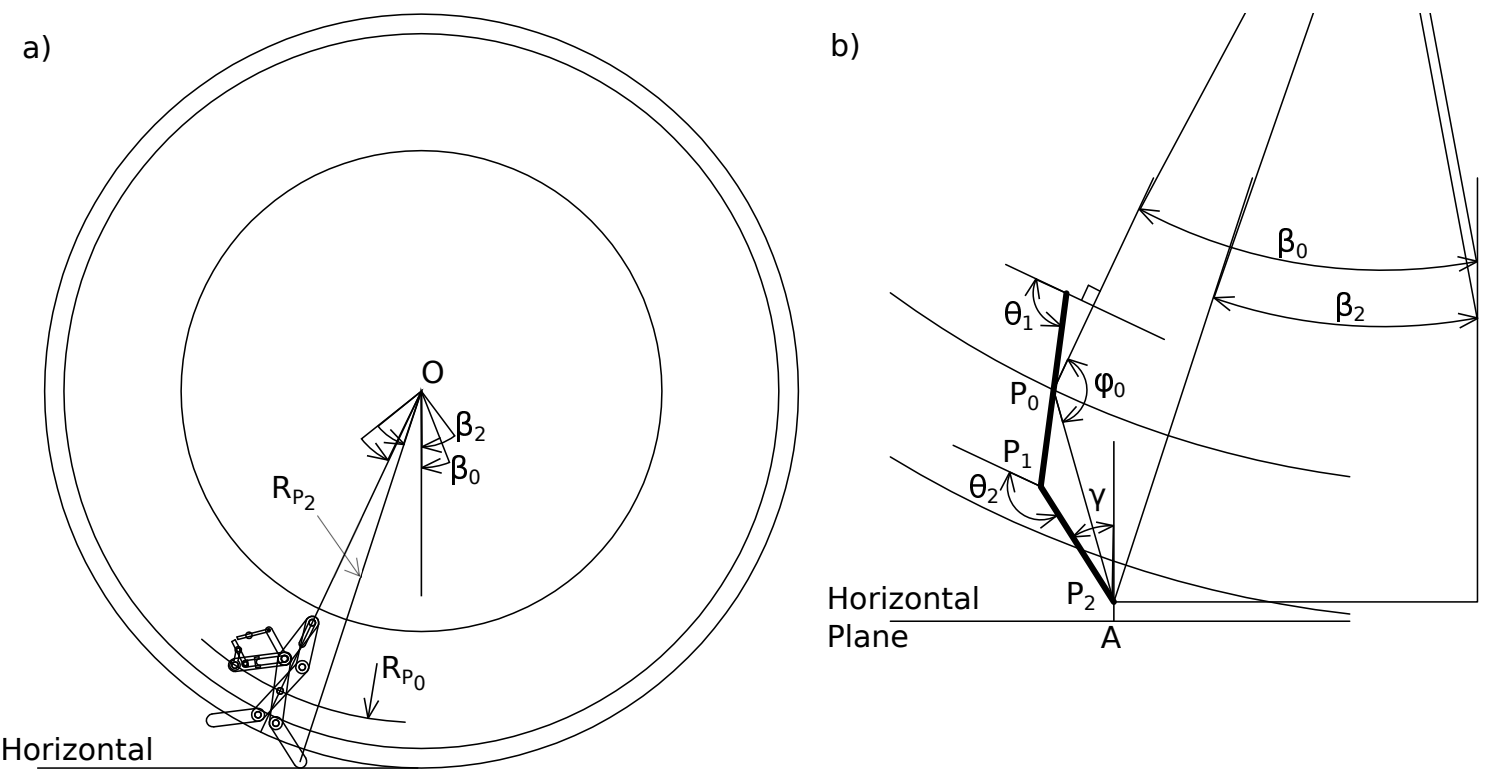

Plane

Figure 5. (a) View showing situation when link 2 touches the plane; (b) detailed view.

$$
\gamma=\angle P_{0} P_{2} O+\angle P_{0} P_{2} P_{1}-\beta_{2}
$$

where,

$$
\begin{aligned}
d_{P_{0} P_{2}} & =\sqrt{d_{P_{0} P_{1}}^{2}+d_{P_{1} P_{2}}^{2}-2 d_{P_{0} P_{1}} d_{P_{1} P_{2}} \cos \left(\pi-\theta_{2}+\theta_{1}\right)} \\
\phi_{0} & =\frac{3 \pi}{2}-\theta_{1}-\cos ^{-1}\left(\frac{d_{P_{0} P_{1}}^{2}+d_{P_{0} P_{2}}^{2}-d_{P_{1} P_{2}}^{2}}{2 d_{P_{0} P_{1}} d_{P_{0} P_{2}}}\right) \\
R_{P_{2}} & =\sqrt{d_{P_{0} P_{2}}^{2}+R_{P_{0}}^{2}-2 d_{P_{0} P_{2}} R_{P_{0}} x \cos \left(\phi_{0}\right)} \\
\beta_{2} & =\cos ^{-1}\left(\frac{R_{T}-d}{R_{P_{2}}}\right) \\
\angle P_{0} P_{2} O & =\cos ^{-1}\left(\frac{d_{P_{0} P_{2}}^{2}+R_{P_{2}}^{2}-R_{P_{0}}^{2}}{2 d_{P_{0} P_{2}} R_{P_{2}}}\right) \\
\angle P_{0} P_{2} P_{1} & =\cos ^{-1}\left(\frac{d_{P_{1} P_{2}}^{2}+d_{P_{0} P_{2}}^{2}-d_{P_{0} P_{1}}^{2}}{2 d_{P_{1} P_{2}} d_{P_{0} P_{2}}}\right)
\end{aligned}
$$

where $d$ is the vertical distance between point $P_{2}$ and $A$ and equal to half of the width of the link 2 . The angle made by link 2 with a vertical is given by $\gamma$. 
It may be noticed that, in a proposed mechanism, link 1 and link 2 are not parallel. Figure 6 illustrates the forces when link 2 touches the horizontal plane. Figure 6a represents the case when link 1 and link 2 are not parallel, whereas Figure $6 \mathrm{~b}$ represents the case when link 1 and link 2 are parallel. The moment at point $P_{0}$ due to the resultant forces are given by:

$$
M_{P_{0}}=f d_{P_{0} P_{2}} \sin \left(\gamma-\angle P_{0} P_{2} P_{1}\right)
$$

In Equation (2), $\gamma$ for the case when link 1 is parallel to link 2, as shown in Figure $6 \mathrm{~b}$ is negative and for the case when link 1 is parallel to link 2 are not parallel, as shown in Figure $6 \mathrm{a} \gamma$ is positive. In the first case, the resultant moment $\left(M_{P_{0}}\right)$, about point $P_{0}$, is in a counter-clockwise direction if the $\angle P_{0} P_{2} P_{1}$ is smaller than $\gamma$. However, the resultant moment $\left(M_{P_{0}}\right)$ in the second case is in a clockwise direction. The resultant counter-clockwise moment in the first case will force link 2 to rotate in a counter-clockwise direction resulting in switching the mechanism to a closed position from the open position. This has two major advantages over the second case-first, saving the energy required by passively switching the mechanism from open to closed position. Second, avoid jerks on the wheel as in the second case the wheel will roll over the tip of the link 2.
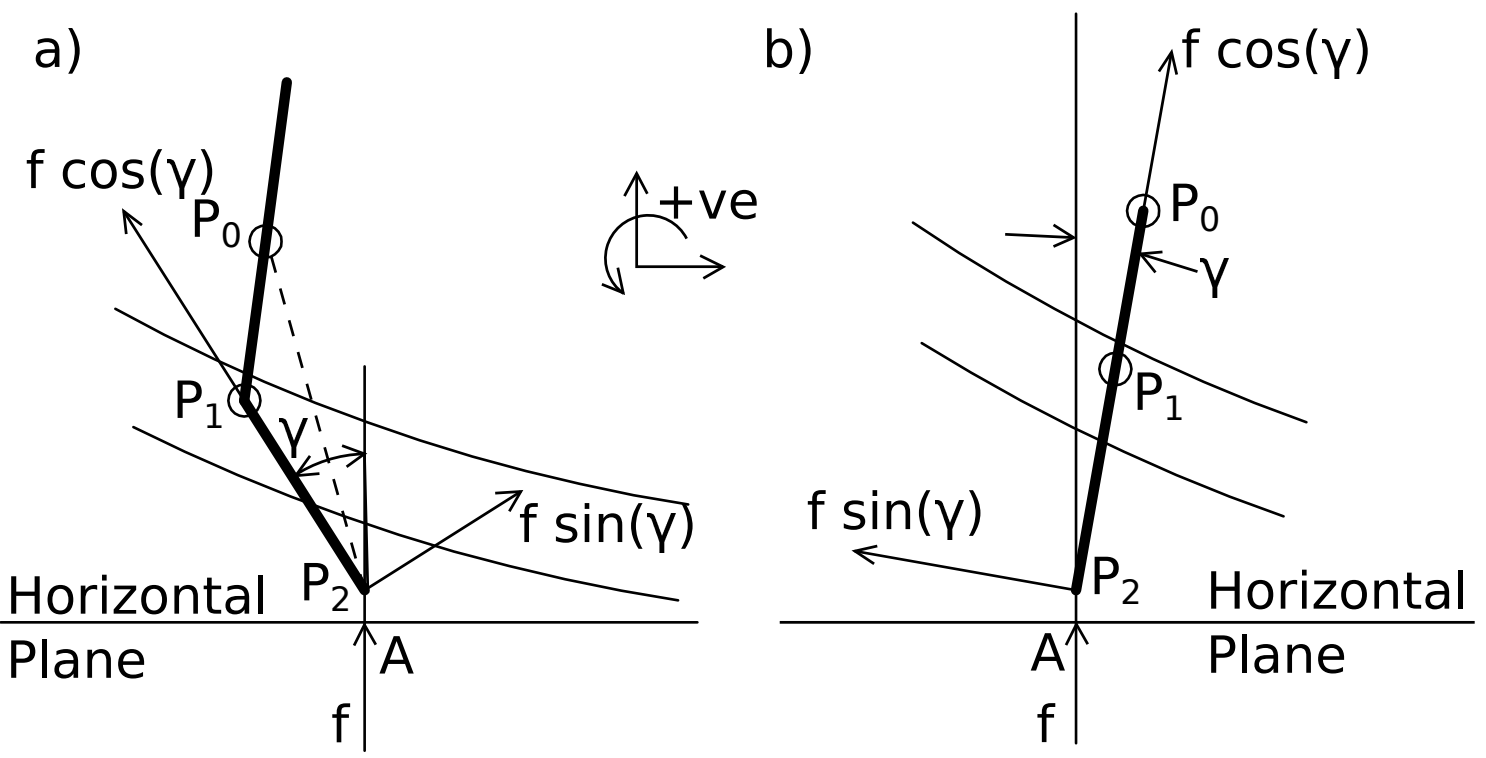

Figure 6. Force equilibrium diagram when link 2 touches the horizontal plane (a) link 1 and link 2 are not parallel; (b) link 1 and link 2 are parallel.

Figure 7 shows the situation where the anti-slip mechanism is in the open position and the wheels are ascending the stairs. Figure 7a represents the mechanism having a fixed angle between link 1 and link 2, whereas, in Figure 7b, the joint between link 1 and link 2 is equipped with a torsional spring. This allows link 2 to rotate with respect to link 1 until link 2 is parallel to link 1 . Such flexibility is an essential feature for the mechanism to function effectively. It may be observed from the first case that the net moment about point $P_{0}$ due to the reaction force at the point of contact between link 1 with the surface of step is in a counter-clockwise direction. Hence, the mechanism will switch to a closed position before the wheel touches the edge of the subsequent step. This may lead to a slipping of the wheel, jeopardizing the ascent of the robot. However, in the second case, the net moment due to the contact force will be in a clockwise direction. Since the links are designed in a way that the maximum angle between link 1 and link 2 is limited to $180^{\circ}$, the mechanism will remain active until climbing on a subsequent step is initiated. 
a)

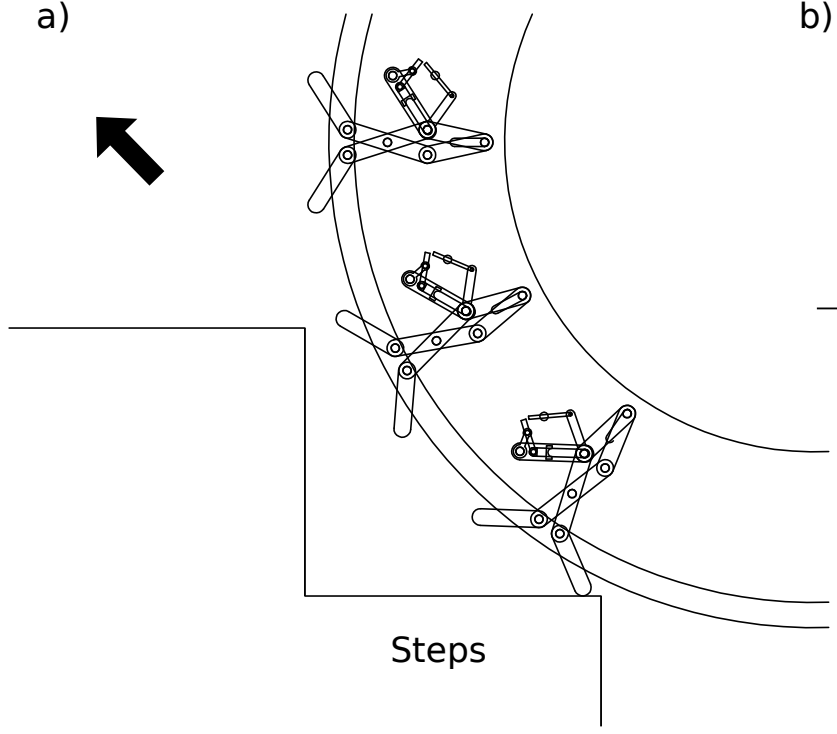

b)

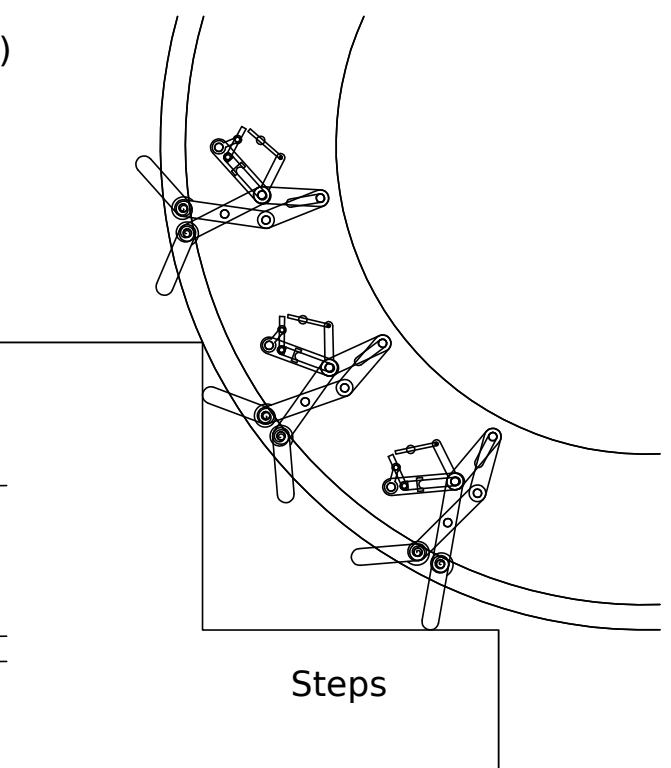

Figure 7. Schematic view showing the section of a wheel while ascending the stairs (a) without torsion spring at joint $P_{1}$; (b) with torsion spring at joint $P_{1}$.

Figure 8a represents a schematic view of half of the clamping mechanism as the other half of the mechanism operates symmetrically. In this section, kinematics of chain 1 are discussed. For a given distance between point $P_{0}$ and the center of the wheel ' $\mathrm{O}$ ', the locus of the point $P_{2}$ with respect to the position of point $P_{4}$ is traced. Using these equations, the position and length $\left(L_{S 1}\right)$ of the slot are determined. This ensures the successful operation of the clamping mechanism. From the figure, it may be noticed that locus of point $P_{2}$ intersects two circles at points 'A' and ' $\mathrm{B}$ '. These circles are at an offset of $L_{w} / 2$ ( $L_{w}$ is width of link 2 ) from the perimeter of tire and outer perimeter of the base plate, respectively. Figure $8 \mathrm{~b}$ shows the detailed view of point ' $A$ '. It may be noticed that the locus of point $P_{2}$ intersects a circle at an offset of $L_{w} / 2$ from the perimeter of the tire. This is because of the width of link 2. Equations to express the maximum and minimum angle for link 1 are mentioned below.

a)

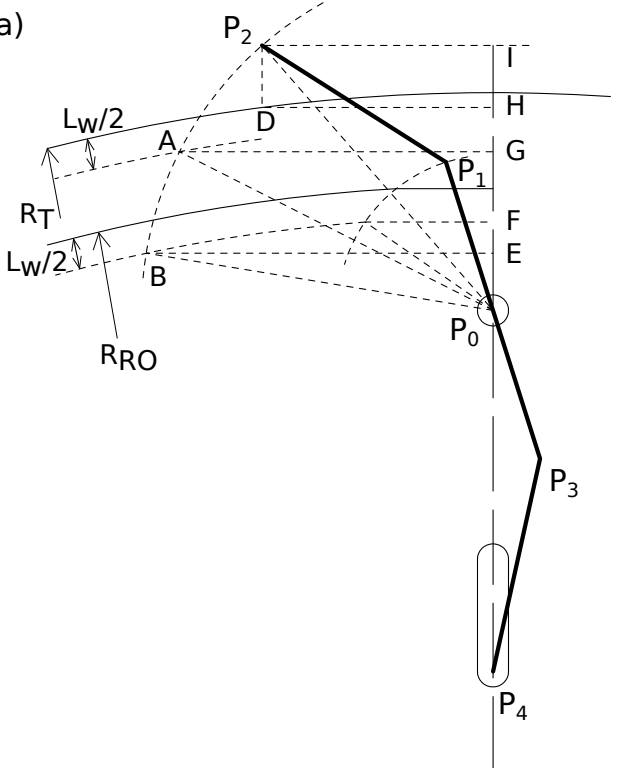

b)

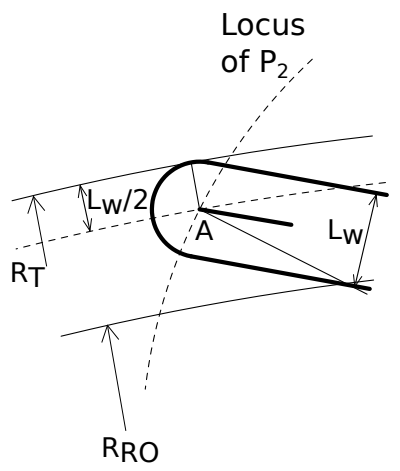

Figure 8. (a) Schematic view of chain 1; (b) detailed view of point A. 


$$
\begin{gathered}
d_{P_{0} P_{2}}=\sqrt{d_{P_{2} I}^{2}+\left(d_{P_{2} D}+d_{H P_{0}}\right)^{2}} \\
R_{T}=\sqrt{d_{P_{2} I}^{2}+\left(d_{H P_{0}}+d_{P_{0} O}\right)^{2}} \quad\left[R_{D}=R_{T}\right]
\end{gathered}
$$

Subtracting Equation (4) from Equation (3);

$$
\begin{aligned}
& d_{H P_{0}}= \frac{d_{P_{0} P_{2}}^{2}-R_{T}^{2}-d_{P_{2} D}^{2}+d_{P_{0} O}^{2}}{2\left(d_{P_{2} D}-d_{P_{0} O}\right)} \\
& \alpha_{P_{2}}=\cos ^{-1}\left(\frac{d_{P_{2} D}+d_{H P_{0}}}{d_{P_{0} P_{2}}}\right) \\
& \theta_{1}^{P_{2}}=90^{\circ}+\left(\alpha_{P_{2}}-\angle P_{1} P_{0} P_{2}\right) \\
& d_{P_{0} P_{4}}^{P_{2}}=d_{P_{0} P_{3}} \cos \left(\theta_{1}^{P_{2}}-90^{\circ}\right)+\sqrt{\left(d_{P_{0} P_{3}} \sin \left(\theta_{1}^{P_{2}}-90^{\circ}\right)\right)^{2}+d_{P_{3} P_{4}}^{2}}
\end{aligned}
$$

where $\alpha_{i}$ is the acute angle made by point $i$ with the vertical and vertex at $P_{0} . \theta_{1}^{k}$ is the angle made by link 1 with horizontal in a counterclockwise direction and $d_{P_{0} P_{4}}^{k}$ is the distance between point $P_{0}$ and $P_{4}$, when the tip of link 2 is at point k.

For a given $d_{P_{0} O}$ (distance between point $P_{0}$ and center of wheel) and $d_{P_{2} D}$ (distance between point $P_{2}$ and periphery of the tire), $\theta_{1}$ and $d_{P_{0} P_{4}}$ are calculated. Similarly, a formula to obtain $d_{P_{0} P_{4}}^{A}$ is given by:

$$
\begin{aligned}
d_{G P_{0}} & =\frac{\left(R_{T}-L_{w} / 2\right)^{2}-d_{P_{0} P_{2}}^{2}-d_{P_{0} O}^{2}}{2 d_{P_{0} O}} \\
\alpha_{A} & =\cos ^{-1}\left(\frac{d_{G P_{0}}}{d_{P_{0} P_{2}}}\right) \\
\theta_{1}^{A} & =90^{\circ}+\left(\alpha_{A}-\angle P_{1} P_{0} A\right) \\
d_{P_{0} P_{4}}^{A} & =d_{P_{0} P_{3}} \cos \left(\theta_{1}^{A}-90^{\circ}\right)+\sqrt{\left(d_{P_{0} P_{3}} \sin \left(\theta_{1}^{A}-90^{\circ}\right)\right)^{2}+d_{P_{3} P_{4}}^{2}}
\end{aligned}
$$

A formula for $d_{P_{0} P_{4}}^{B}$ is given by:

$$
\begin{aligned}
d_{E P_{0}} & =\frac{\left(R_{R O}-L_{w} / 2\right)^{2}-d_{P_{0} P_{2}}^{2}-d_{P_{0} O}^{2}}{2 d_{P_{0} O}} \\
\alpha_{B} & =\cos ^{-1}\left(\frac{d_{E P_{0}}}{d_{P_{0} P_{2}}}\right) \\
\theta_{1}^{B} & =90^{\circ}+\left(\alpha_{B}-\angle P_{1} P_{0} A\right) \\
d_{P_{0} P_{4}}^{B} & =d_{P_{0} P_{3}} \cos \left(\theta_{1}^{B}-90^{\circ}\right)+\sqrt{\left(d_{P_{0} P_{3}} \sin \left(\theta_{1}^{B}-90^{\circ}\right)\right)^{2}+d_{P_{3} P_{4}}^{2}}
\end{aligned}
$$

subtracting Equation (9) from Equation (7), length $L_{S 1}$ may be determined.

The number of anti-slip mechanisms on a wheel depends on the outer diameter of the rim of a wheel. All the mechanisms are mounted on a plate, called the base plate, and then attached to the wheel. The outer diameter of the base plate will be equal to the outer diameter of the rim of the wheel. A minimum number of mechanisms required is given by Equation (10):

$$
N=\frac{360^{\circ}}{\alpha_{B}}
$$

The number of mechanisms attached to the base plate is the nearest integer value greater than N. Since two such base plates are attached to either side of the wheel, the number of the mechanism attached to a wheel is twice as in a single base plate. 


\subsection{Chain 2: Bi-Stable Four Bar Mechanism}

The two positions of the anti-slip wheel mechanism, i.e., open and closed position, are achieved by using a bi-stable four-bar mechanism. A four-bar mechanism where a torsion spring is attached to one of the joints resulting in two stable positions is known as a bi-stable four-bar mechanism. In Figure 9a, a schematic view of the proposed bi-stable mechanism is shown. A torsion spring is attached at a joint $P_{6}$. Two stable positions of link 1 are shown in Figure $9 \mathrm{~b}$ by the line joining point $P_{0}$ and $P_{3}$, and $P_{0}$ and $P_{3}^{\prime \prime}$. In addition, a critical position is shown in the figure by a line joining $P_{0}$ and $P_{3}^{\prime}$. At this position, link 1 and link 4 are parallel and the mechanism may be stuck in this position. Hence, for the successful operation of the proposed mechanism design, parameters are chosen to avoid the critical position.

a)

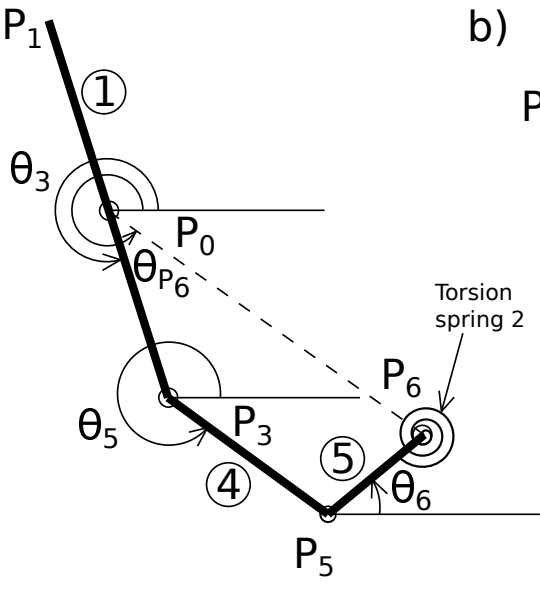

b)

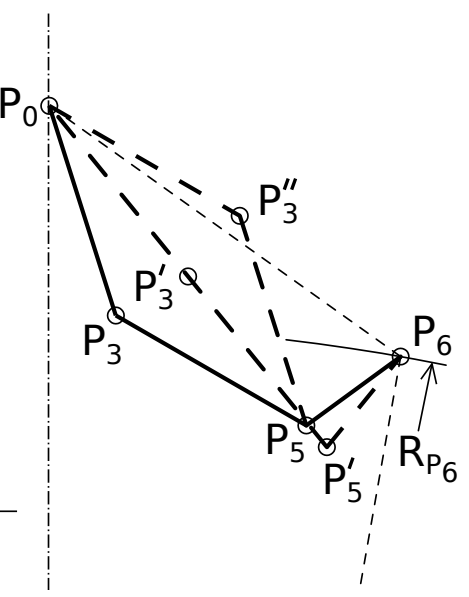

Figure 9. (a) Schematic view of chain 2; (b) two stable positions on bi-stable mechanism.

$$
\begin{array}{rlrl}
d_{P_{0} P_{6}} & =\sqrt{d_{P_{0} O}^{2}+d_{O P_{6}}^{2}-2 d_{P_{0} O} d_{O P_{6}} \cos \beta_{6}} \\
\theta_{3} & =\theta_{1}+180^{\circ} \\
d_{P_{3} P_{6}} & =\sqrt{d_{P_{0} P_{3}}^{2}+d_{P_{0} P_{6}}^{2}-2 d_{P_{0} P_{3}} d_{P_{0} P_{6}} \cos \left(\theta_{P_{6}}-\theta_{3}\right)} \\
\angle P_{0} P_{6} P_{3} & =\cos ^{-1}\left(\frac{d_{P_{0} P_{6}}^{2}+d_{P_{3} P_{6}}^{2}-d_{P_{0} P_{3}}^{2}}{2 d_{P_{0} P_{6}} d_{P_{3} P_{6}}}\right) & \\
\angle P_{3} P_{6} P_{5} & =\cos ^{-1}\left(\frac{d_{P_{3} P_{6}}^{2}+d_{P_{5} P_{6}}^{2}-d_{P_{3} P_{5}}^{2}}{2 d_{P_{3} P_{6}} d_{P_{5} P_{6}}}\right) & \\
\theta_{6} & =\theta_{P_{6}}+\angle P_{0} P_{6} P_{3}+\angle P_{3} P_{6} P_{5}-360^{\circ} & & {\left[\text { For } \theta_{3} \leq \theta_{P_{6}}\right]} \\
\theta_{6} & =\theta_{P_{6}}-\angle P_{0} P_{6} P_{3}+\angle P_{3} P_{6} P_{5}-360^{\circ} & & {\left[\text { For } \theta_{3}>\theta_{P_{6}}\right]}
\end{array}
$$

Critical angle for link 1 is given by following equation:-

$$
\theta_{3_{C R}}=\cos ^{-1}\left(\frac{\left(d_{P_{0} P_{3}^{\prime}}+d_{P_{3}^{\prime} P_{5}^{\prime}}\right)^{2}+d_{P_{0} P_{6}}^{2}-d_{P_{5}^{\prime} P_{6}}^{2}}{2\left(d_{P_{0} P_{3}^{\prime}}+d_{P_{3}^{\prime} P_{5}^{\prime}}\right) d_{P_{0} P_{6}}}\right)
$$

The link dimensions must be chosen in a way that, during passive switching, the mechanism from the open to the closed position the angle $\theta_{3}$ must be more than $\theta_{3_{C R}}$ whereas, during active switching from a closed position to an open position, angle $\theta_{3}$ must be less than $\theta_{3_{C R}}$. 


\subsection{Chain 3: Actuator Mechanism}

To actuate the mechanism, an actuator based on a shape memory alloy (SMA) is used. Figure 10a represents the schematic of the actuation mechanism. An SMA wire is installed between point $P_{7}$ and point $P_{10}$. When a current is passed through the SMA wire, due to the electrical resistance of the wire, the temperature of the wire rises. This results in shrinkage of the wire. The points $P_{8}, P_{11}$, and $P_{3}$ are constrained to move along the link 6 with the help of a slot. A linear spring is attached between point $P_{8}$ and $P_{11}$. As the SMA wire shrinks, the distance between point $P_{7}$ and $P_{8}$ increases, pushing the point $P_{3}$ to switch the mechanism from a closed to an open position.

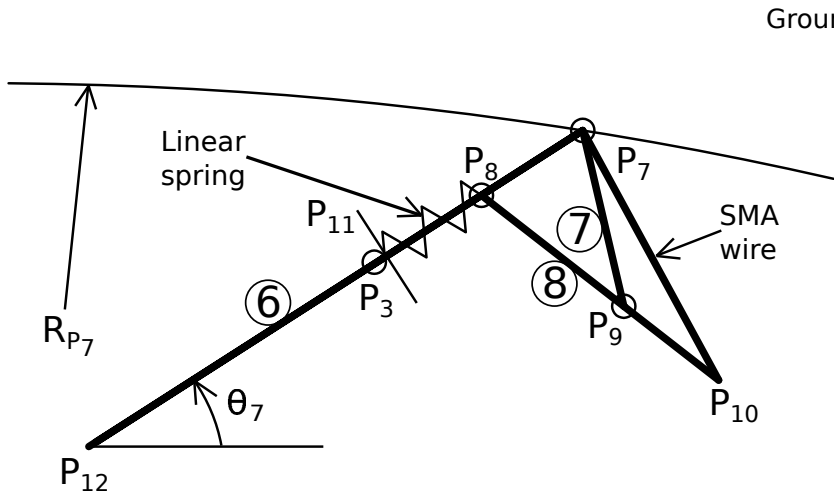

(a)

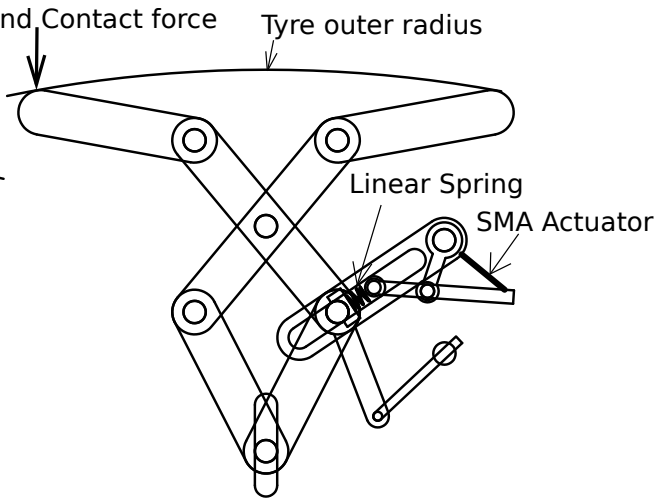

(b)

Figure 10. (a) Schematic view of chain 3; (b) situation when the ground force pushes the mechanism to a closed position but the actuator in an open position.

It may be noticed that point $P_{3}$ represents the joint between link 1 and link 3 , whereas $P_{11}$ represents the endpoint of linear spring. In the closed position, these two points will be in the same position due to the force exerted by the linear spring. However, during the open position of the mechanism, the points will be in separate positions. Figure 10b illustrates a situation when the ground force pushes the anti-slip mechanism to a closed position, but the SMA actuator is powered on. Such situation may arise when the robot is on an intermediate platform while climbing on the stairs. It may be noticed from the figure that, although the ground force pushes the mechanism to closed position, since the actuator is powered on, a deflection in link 2 results in compression of a linear spring. The energy stored during compression of a linear spring will push the linkage to an open position as soon as the ground contact force vanishes. Use of a linear spring in between the actuation mechanism and clamping mechanism has two benefits. Firstly, it helps in reducing the impact on the actuator. Secondly, any force pushing the mechanism to a closed position, when the actuator is powered on, it pushes the mechanism to an open position upon withdrawal of the force. This results in keeping the mechanism open for any subsequent climbing:

$$
\begin{aligned}
d_{P_{7} P_{3}} & =\sqrt{\left(P_{7_{x}}-P_{3_{x}}\right)^{2}+\left(P_{7_{y}}-P_{3_{y}}\right)^{2}} \\
d_{P_{7} P_{8}} & =d_{P_{7} P_{3}}-d_{P_{8} P_{11}}\left[d_{P_{8} P_{11}}=\text { Lenght of linear spring }\right] \\
\angle P_{7} P_{9} P_{8} & =\cos ^{-1}\left(\frac{d_{P_{7} P_{9}}^{2}+d_{P_{8} P_{9}}^{2}-d_{P_{7} P_{8}}^{2}}{2 d_{P_{7} P_{9}} d_{P_{8} P_{9}}}\right) \\
\angle P_{7} P_{9} P_{10} & =180^{\circ}-\angle P_{7} P_{9} P_{8} \\
d_{P_{7} P_{10}} & =\sqrt{d_{P_{7} P_{9}}^{2}+d_{P_{9} P_{10}}^{2}-2 d_{P_{7} P_{9}} d_{P_{9} P_{10}} \cos \left(\angle P_{7} P_{9} P_{10}\right)}
\end{aligned}
$$

where $P_{i_{x}}$ is the projection point $P_{i}$ on the $x$-axis and $P_{i_{y}}$ is the projection point $P_{i}$ on the $y$ axis (with origin of the co-ordinate system at the center of the wheel). Equation (14) is used to determine the distance between point $P_{7}$ and $P_{10}$ at different stages of the mechanism. 


\subsection{Force Requirement of the SMA Actuator}

In this section, the force required achieving the variation in the actuator length is discussed. Figure 11 represents the schematic of chain 2 and chain 3 . It may be noticed that the SMA wire must generate enough force to overcome the torque generated by the torsional spring 2 while rotating link 5 from point $P_{5}$ to point $P_{5}^{\prime}$. Point $P_{5}^{\prime}$ represents the case when the bi-stable four-bar mechanism is at a critical state.

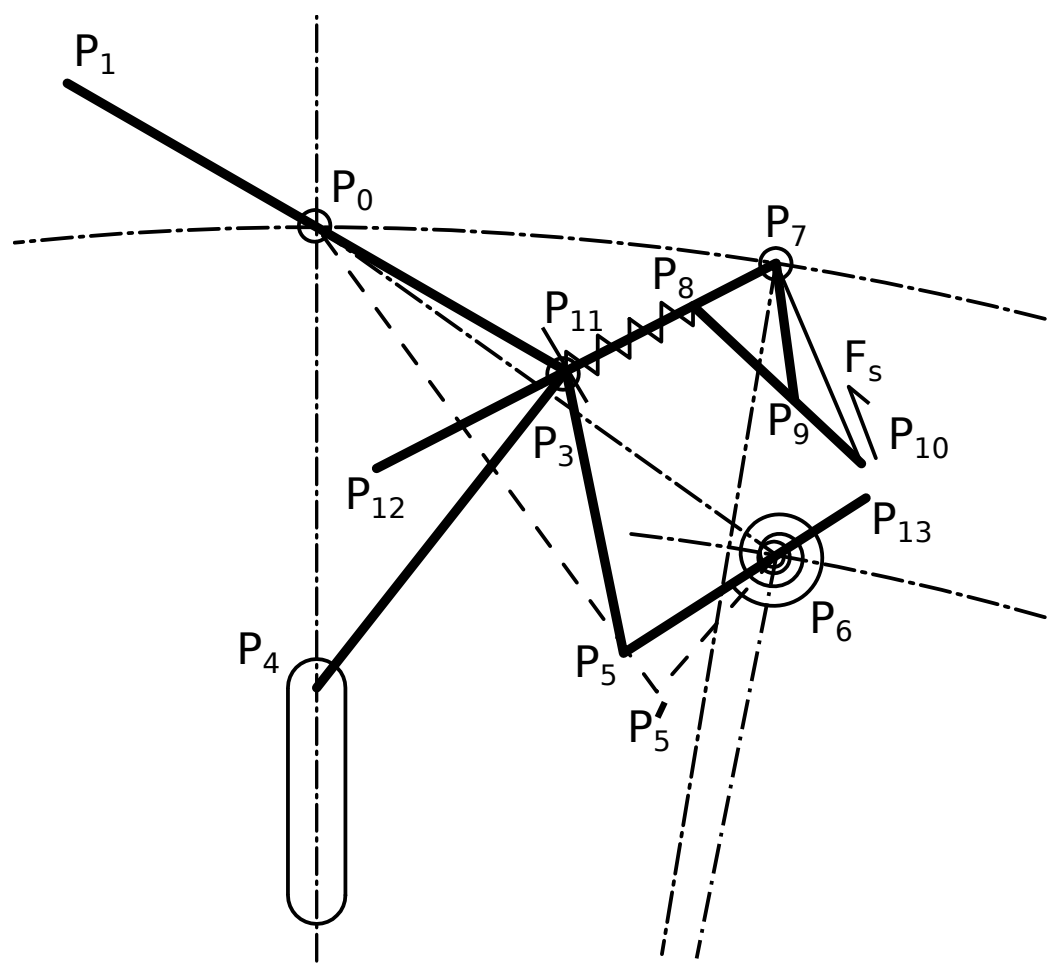

Figure 11. Schematic view of chain 3 and chain 2 for SMA force calculation.

The relationship to derive the maximum force required by the actuator for the successful operation of the mechanism is based on the virtual work method. The maximum force required to push point $P_{3}$ beyond will be at the critical position of the bi-stable mechanism as the resistivity torque by the torsion spring 2 will be the maximum at this position:

$$
\begin{aligned}
F \delta S & =T \delta \theta \\
F & =\tau \Delta \theta \frac{\delta \theta}{\delta S} \quad[T=\tau \Delta \theta]
\end{aligned}
$$

where $\delta S$ is the infinitesimal change in distance between point $P_{7}$ and $P_{10} . T$ is the torque generated by the torsional spring 2 , and $\delta \theta$ is the infinitesimal change in angle $\theta_{6}$ with respect to $\delta S . \tau$ is the stiffness of the torsional spring. $\Delta \theta$ is the difference in the angle made by link 5 with a horizontal at the closed position and the critical position:

$$
\begin{aligned}
d_{P_{0} P_{7}} & =\sqrt{2 R_{P_{0}}^{2}\left(1-\cos \beta_{7}\right)} \\
\angle P_{7} P_{0} P_{3} & =\cos ^{-1}\left(\frac{d_{P_{0} P_{3}}^{2}+d_{P_{0} P_{7}}^{2}-d_{P_{3} P_{7}}^{2}}{2 d_{P_{0} P_{3}} d_{P_{0} P_{7}}}\right) \\
\theta_{3} & =\theta_{P_{0} P_{7}}-\angle P_{7} P_{0} P_{3}
\end{aligned}
$$

where $\theta_{P_{0} P_{7}}$ is the angle made by line joining point $P_{0}$ and point $P_{7}$ with the horizontal in a clockwise direction. 
Using Equations (13), (14) and (16) relation between $d_{P_{7} P_{10}}$ and $\theta_{6}$ may be derived at a critical position. Differentiating the relation, the ratio of $\delta \theta$ to $\delta S$ may be derived and given as:

$$
\frac{\delta \theta}{\delta S}=\frac{-d_{P_{7} P_{10}} d_{P_{8} P_{9}} d_{P_{7} P_{11}} d_{P_{0} P_{5}^{\prime}} \sin \angle P_{7} P_{9} P_{8} \cos \angle P_{5}^{\prime} P_{0} P_{6}}{d_{P_{9} P_{10}} d_{P_{7} P_{8}} d_{P_{0} P_{7}} d_{P_{0} P_{3}} d_{P_{5}^{\prime} P_{6}} \sin \angle P_{7} P_{9} P_{10} \sin \angle P_{7} P_{0} P_{11} \cos \angle P_{0} P_{6} P_{5}^{\prime}}
$$

\subsection{Actuation Length of an SMA Actuator}

Actuation length of an actuator is one of the important factors in the designing of the actuator. In Section 3.4, the force required to actuate the mechanism from the closed position to overcome the critical position is discussed. Using this force, the required change in the length of SMA actuator $(\Delta X)$ may be determined. The change in actuator length comprises two components, i.e., change is actuator length due to a change in the length of linear spring $\left(\Delta X_{L}\right)$ and change is actuator length due to a deflection of link $5\left(\Delta X_{\theta}\right)$. The equation of actuation length is given as:

$$
\Delta X=\Delta X_{L}+\Delta X_{\theta}
$$

For an applied force $(F)$ by the SMA actuator which causes deflection of link 5 by $\Delta \theta$, the change in actuator length is given by Equation (15):

$$
\Delta X_{\theta}=\frac{\tau \Delta \theta^{2}}{F}
$$

Change is length of linear spring due to applied force by the actuator being caused by the axial force $\left(F^{\prime}\right)$ on link 6 at point $P_{8}$ :

$$
\begin{aligned}
\Delta X_{L} & =\frac{F^{\prime}}{K} \\
\Delta X_{L} & =\frac{-F d_{P_{7} P_{8}} d_{P_{9} P_{10}} \sin \angle P_{7} P_{9} P_{10}}{K d_{P_{8} P_{9}} d_{P_{7} P_{10}} \sin \angle P_{7} P_{9} P_{8}}
\end{aligned}
$$

Using Equations (19) and 20 in Equation (18), $\Delta X$ may be determined.

\section{Results and Discussion}

An anti-slip wheel mechanism is designed using the equations discussed in Section 3 for a wheel of outer diameter $580 \mathrm{~mm}$. Dimensions of different members are chosen for the successful operation of the proposed mechanism. The dimensions of the members are shown in Table 1.

Table 1. Dimensions of the members of the anti-slip mechanism.

\begin{tabular}{cccc}
\hline Parameters & Values & Parameters & Values \\
\hline Link 1 & $35 \mathrm{~mm}$ & $R_{T}$ & $290 \mathrm{~mm}$ \\
Link 2 & $50 \mathrm{~mm}$ & $R_{R O}$ & $275 \mathrm{~mm}$ \\
Link 3 & $35 \mathrm{~mm}$ & $R_{R I}$ & $185 \mathrm{~mm}$ \\
Link 4 & $25 \mathrm{~mm}$ & $R_{P_{0}}$ & $255 \mathrm{~mm}$ \\
Link 5 & $50 \mathrm{~mm}$ & $R_{P_{6}}$ & $230 \mathrm{~mm}$ \\
Link 6 & $42 \mathrm{~mm}$ & $L_{S 1}$ & $18 \mathrm{~mm}$ \\
Link 7 & $12 \mathrm{~mm}$ & $\beta_{6}$ & $10^{\circ}$ \\
Link 8 & $30 \mathrm{~mm}$ & $\beta_{7}$ & $9^{\circ}$ \\
Spring length & $10 \mathrm{~mm}$ & $\alpha$ & $140^{\circ}$ \\
\hline
\end{tabular}

It is found that 13 such mechanisms should be attached to one side of the wheel. To minimize the load distribution at the tip of link 2, another set of the proposed mechanism is attached to the other side of the wheel. Hence, 26 mechanisms (13 on either side of 
the wheel) with the dimensions mentioned in Table 1 should be attached to the wheel of diameter $580 \mathrm{~mm}$.

\subsection{Stress Analysis}

The developed 3D model is used to perform stress analysis. Figures 12 and 13 represent different views of the developed 3D model. Figure 12a shows the front view of the model when the mechanism is in an open position. It may be noticed that the tip of link 2 is protruded outside the outer diameter of the wheel. This will allow the mechanism to clamp on the edge of the steps. Figure $12 \mathrm{~b}$ shows the side view of the 3D model. This figure illustrates the mounting of two anti-slip mechanisms on either side of the wheel. This results in sharing the load on the individual wheel. Figure 13 shows a perspective view of the developed model.
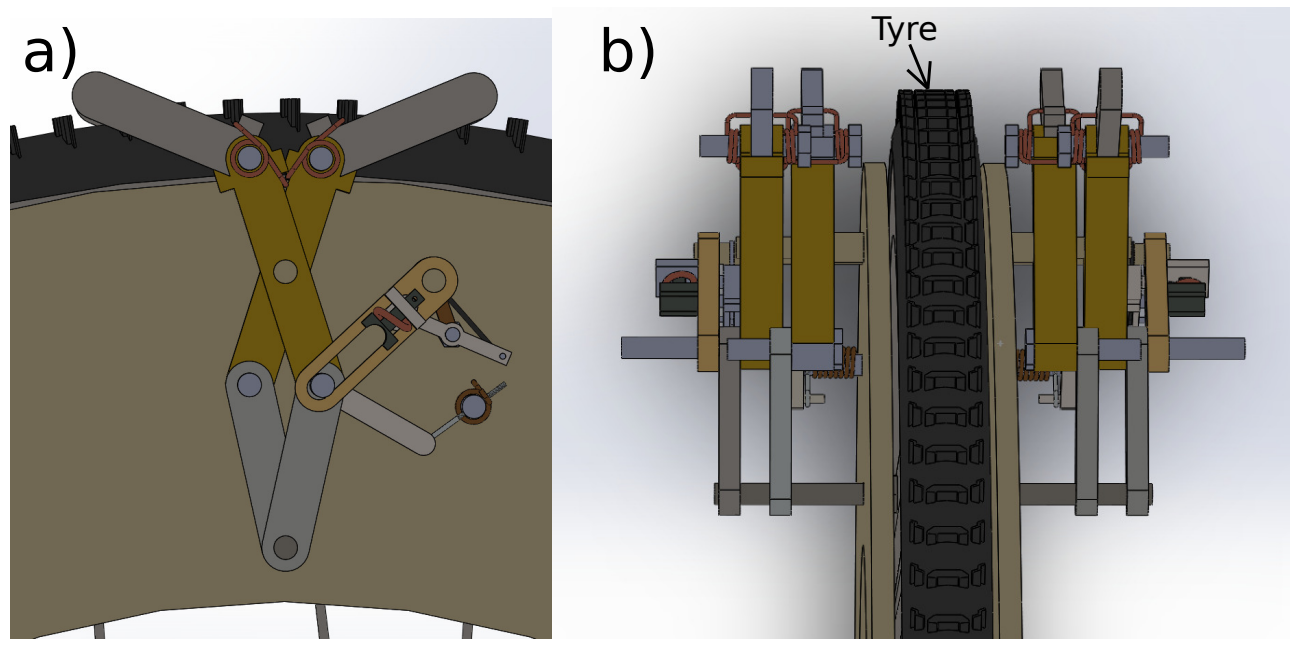

Figure 12. 3D model of anti-slip wheel mechanism (a) front view; (b) side view.

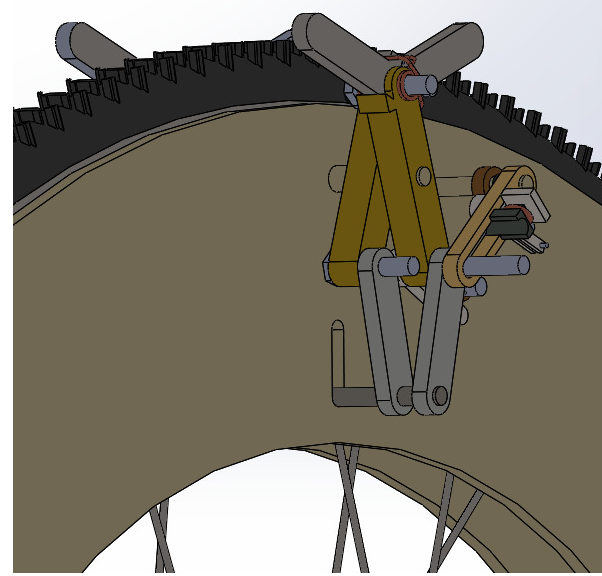

Figure 13. Perspective view of the 3D model of the anti-slip wheel mechanism.

Stress analysis is performed on chain 1 of the mechanism, chain 1 experiences the maximum external loads during its engagement with the edge of the stairs. Links' materials are selected as ASTM A36 (structural grade material), having a yield strength of $6.204 \times 10^{8} \mathrm{~N} / \mathrm{m}^{2}$. A load of $250 \mathrm{~N}$ is applied and fixing the base plate as a constraint, Von-Mises stress is evaluated. Table 2 shows the details of finite element analysis. Figures 14 and 15 show different views of the contour plot of Von-Mises stress on different members of chain 1. In Figure 14, location and direction of applied load are displayed. In Figure 15, the point at which maximum Von-Mises stress developed is shown. The max- 
imum of stresses developed in various members of the chain 1 is $2.051 \times 10^{8} \mathrm{~N} / \mathrm{m}^{2}$ and the factor of safety is 3.025. This validated the safety of link members under the applied load of $250 \mathrm{~N}$. Figure 16 represents the deflection on the members under the applied load. The maximum displacement of $0.205 \mathrm{~mm}$ is observed at the tip of link 2 .

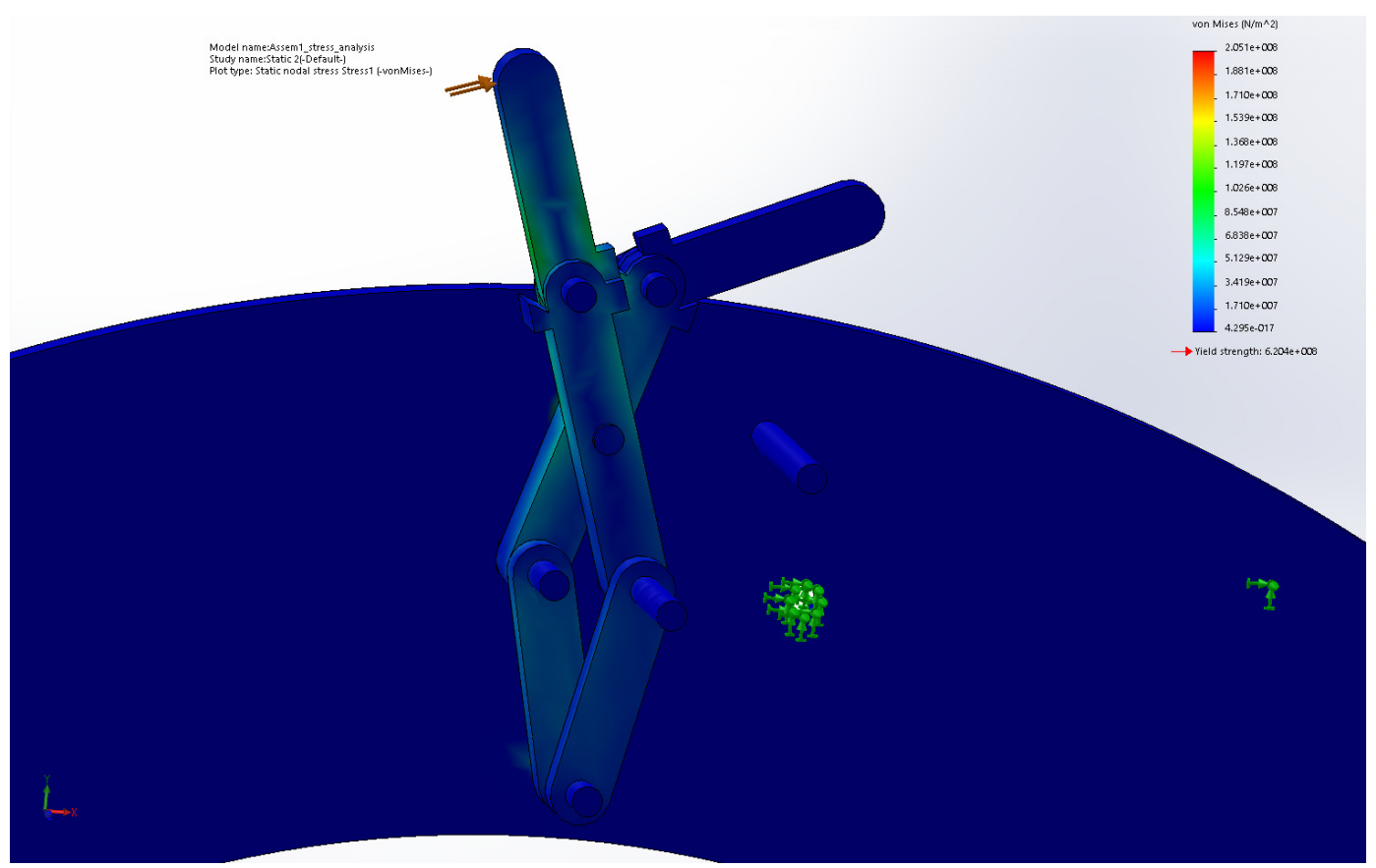

Figure 14. Von-Mises stress on chain 1 due to external loading (View 1).

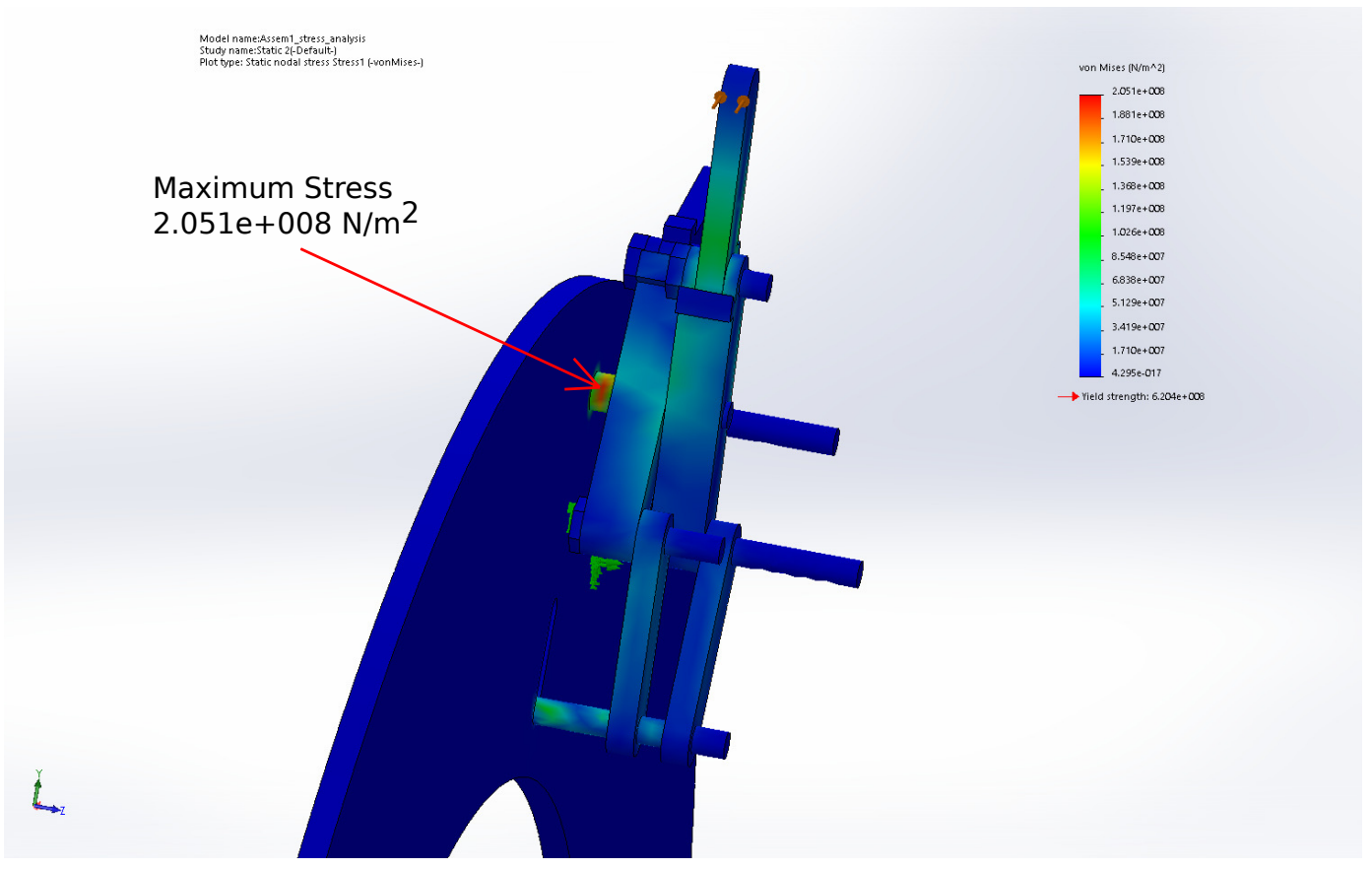

Figure 15. Von-Mises stress on chain 1 due to external loading (View 2). 


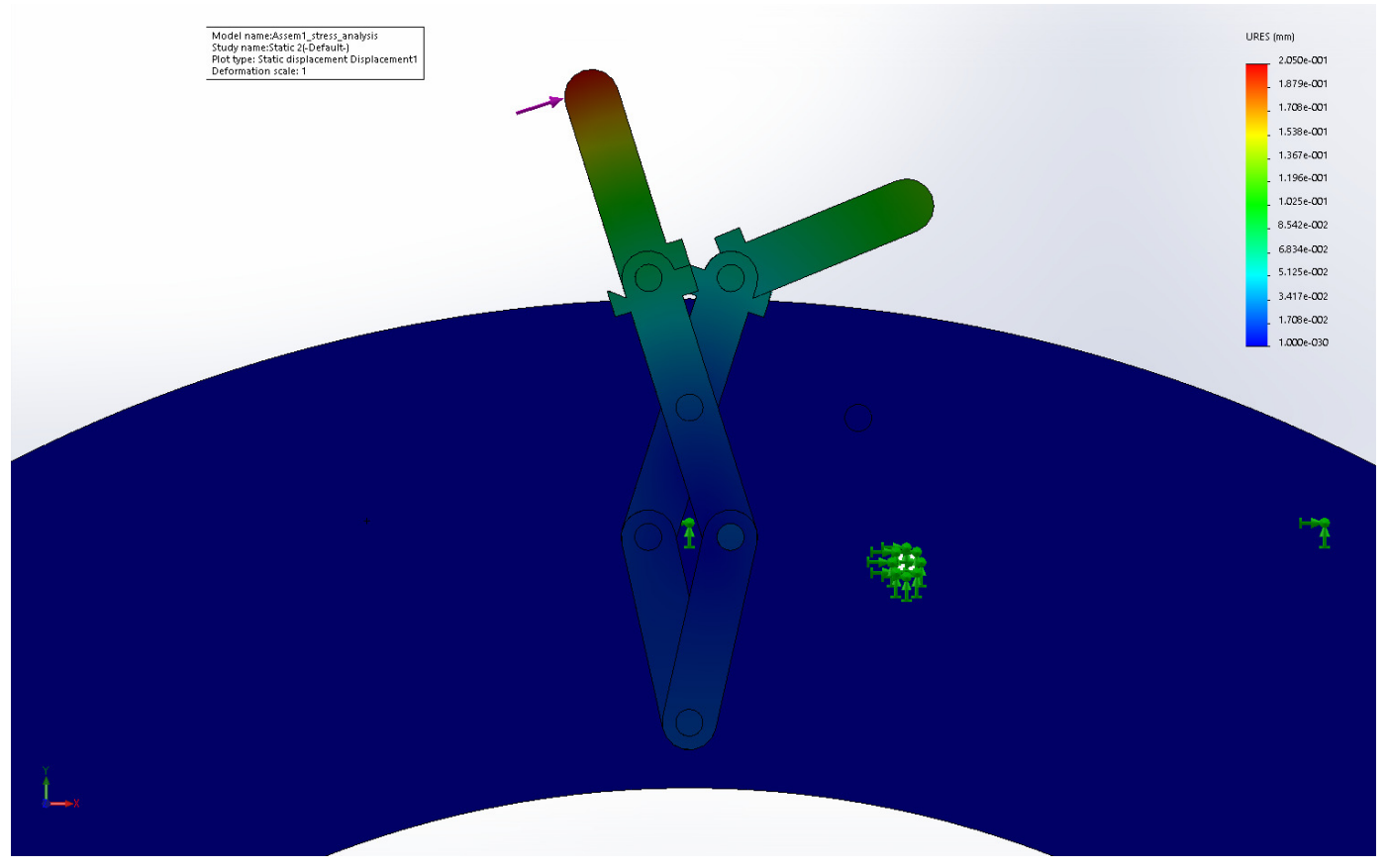

Figure 16. Deflection in members of chain 1 due to external loading.

Table 2. Details of finite element analysis.

\begin{tabular}{ll}
\hline Mesh Details & Values \\
\hline Mesh type & Solid mesh (Tetrahedral) \\
Mesher used & Standard mesh \\
Jacobian points & 4 points \\
Element size & $8.92029 \mathrm{~mm}$ \\
Tolerance & $0.446014 \mathrm{~mm}$ \\
Adaptive Method & None \\
\hline
\end{tabular}

\subsection{Motion Analysis}

To analyze the motion of the proposed mechanism, a 3D model (for link dimension, refer to Table 1) is developed in MSC-Adams. Figure 17a shows the closed position of the mechanism and Figure $17 \mathrm{~b}$ shows the open position. It may be noticed that, in open position, links 2 and 2(a) have moved beyond the radius of the tire. This will ensure clamping by the mechanism on the edge of the stairs.

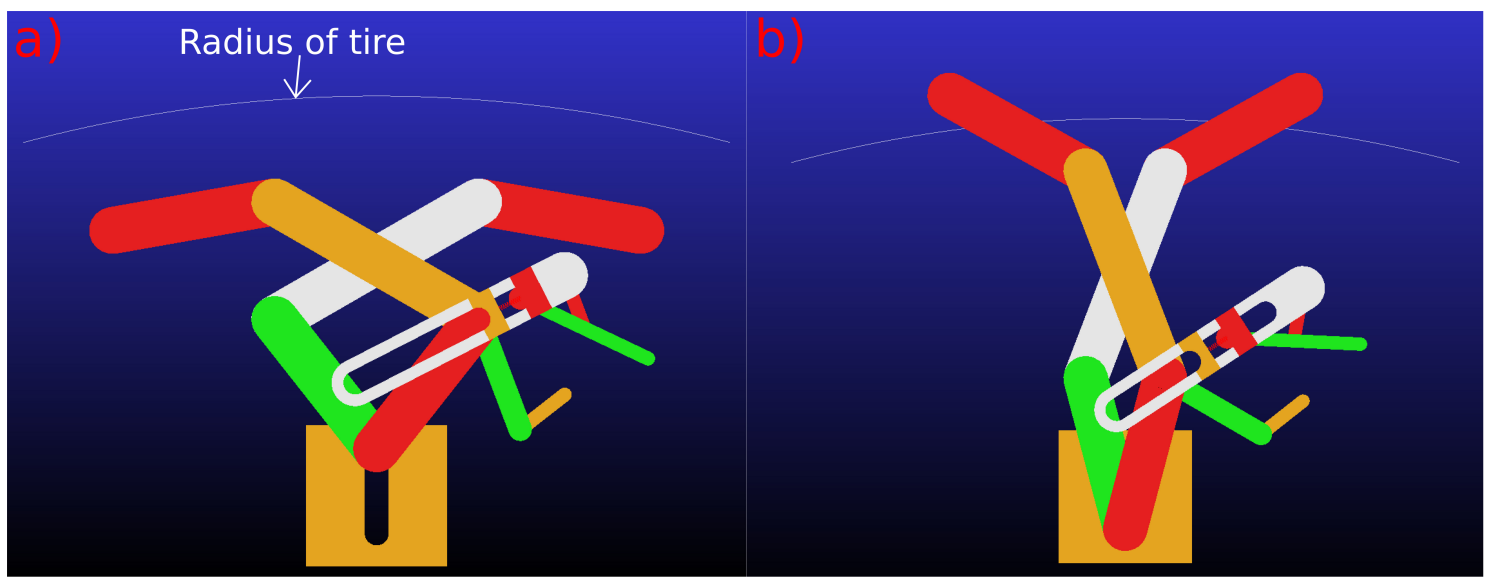

Figure 17. Model of proposed mechanism developed in MSC Adams (a) closed position; (b) open position. 
For the analysis of the mechanism, the coefficient of stiffness of linear spring (between point P8 and P11 of actuator mechanism) is considered as $15 \mathrm{~N} / \mathrm{mm}$. The coefficient of stiffness and damping of torsional spring at point P6 are considered as $5 \mathrm{~N}-\mathrm{mm} / \mathrm{deg}$ and $1 \mathrm{~N}-\mathrm{mm}$-s/deg, respectively. The simulation is performed for $2 \mathrm{~s}$ with 5000 simulation steps. Figure 18a shows the variation of angle of link 1a, the angle between link 1 and link 4 , and the angular deflection of link 5 . It may be noticed that the angle between link 1 and link $4(\angle \mathrm{P} 5 \mathrm{P} 3 \mathrm{P} 0)$ becomes $180^{\circ}$ at $1.13 \mathrm{~s}$. This implies that link 1 and link 4 are inline. Once the mechanism crosses this position, the mechanism moves to its next stable state, which results in the open position of the anti-slip mechanism. In may be observed that the angular displacement of link 5 (link 5 is attached to the torsional spring which forces the mechanism into bi-stable state) reaches $10^{\circ}$ (maximum displacement) and remains unchanged until $1.4 \mathrm{~s}$. This behavior is observed because of the damping of the torsional spring. After $1.4 \mathrm{~s}$, the rate of change of angular displacement increases and the mechanism attains the open position of the anti-slip mechanism. This increase in angular velocity of link 1a and 5 may be observed in Figure 18b.

For actuating the anti-slip mechanism mechanism to the open position, an SMA wire is used (refer to Figure 3). Figure 19a illustrates the variation of force on the SMA wire during the opening of the proposed mechanism. It may be noticed that the maximum force required to be generated by the SMA actuator is $4.7 \mathrm{~N}$. For changing the mechanism position from the closed to open position, the SMA wire should shrink by $7 \mathrm{~mm}$, which may be observed from Figure 19b.

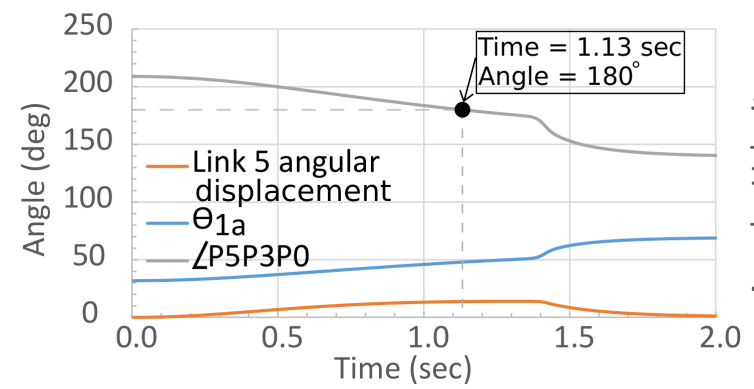

(a)

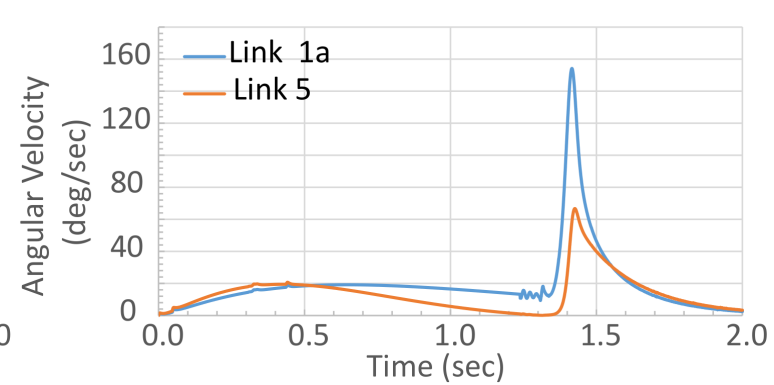

(b)

Figure 18. Kinematics of links 1a and 5 (a) angular displacement; (b) angular velocity.

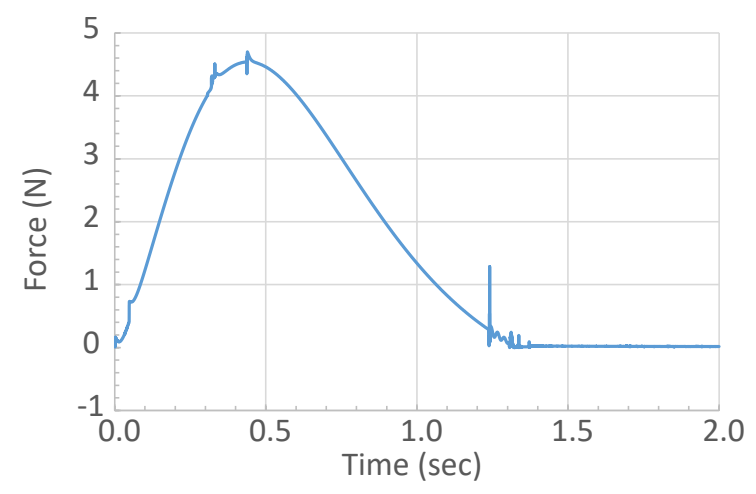

(a)

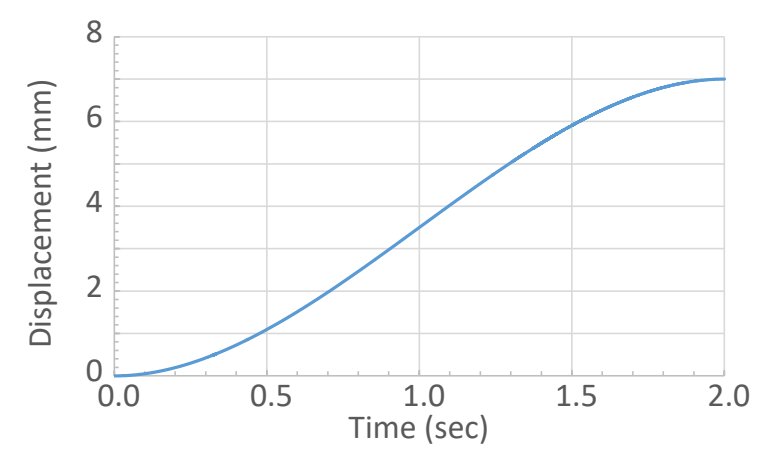

(b)

Figure 19. (a) Force required by SMA actuator; (b) deformation of SMA actuator.

To validate the mechanism, simulations are performed by attaching a single pair of the proposed mechanism to a wheel of diameter $580 \mathrm{~mm}$. The material for step and links are considered to be carbon steel (grade A36), whereas, for the tire, rubber is considered. Figures 20 and 21 shows snapshots of the simulations for ascending and descending, respectively. The zoomed in view of the contact area between link of mechanism and the surface of stair is also shown in the figures. From Figure 20a, it may be observed that 
initially links 1 and 2 are at an angle, whereas, in Figure 20b-d, when link 2 comes in contact with the surface on the stairs, the angle between link 1 and link 2 becomes $180^{\circ}$. The links remain in-line until the angle between link 2 and the surface becomes greater than $90^{\circ}$, which may be observed from Figure 20e. Similarly, Figure 21 illustrates the simulation for descending of the wheel. In Figure 21a, it may be observed that the wheel is not in contact with the edge of the stair. In such condition, a wheel without an anti-slip mechanism will tend to slip off the edge. It may be observed that link 2 of the mechanism is in contact with the surface of the stair, and this helps to prevent the slipping of the wheel.
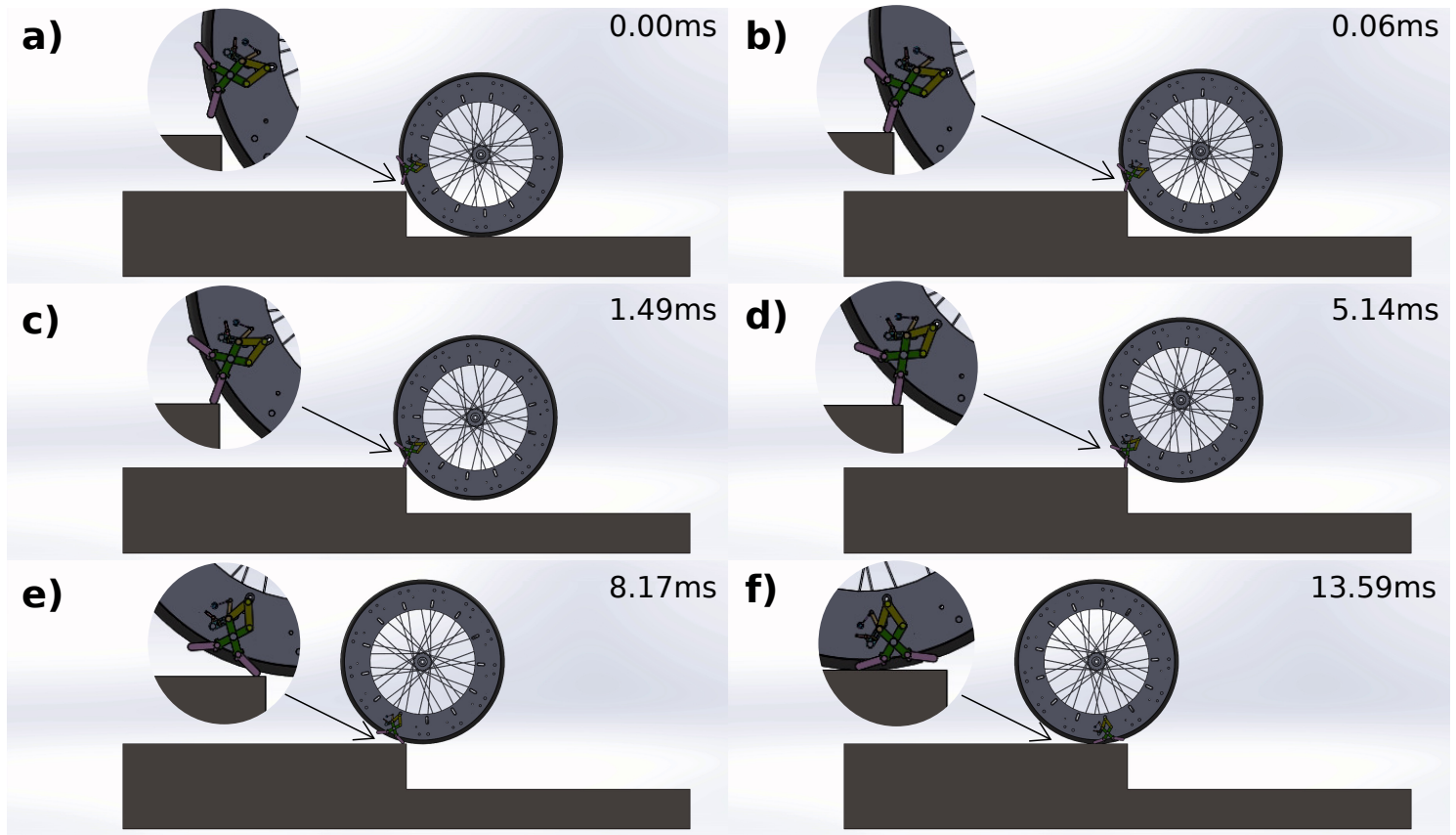

Figure 20. Motion simulation of the mechanism while ascending a step (time stamp in milliseconds are roughly estimated from videos) (a) the tip of link 2 is about to touch the edge of the step; (b) the tip of link 2 touches the edge of the step; (c) link 2 becomes parallel to link 1; (d) wheel climbs half way; (e) as the climbing is about to complete link 2 returns to initial position; (f) climbing is complete.

a)

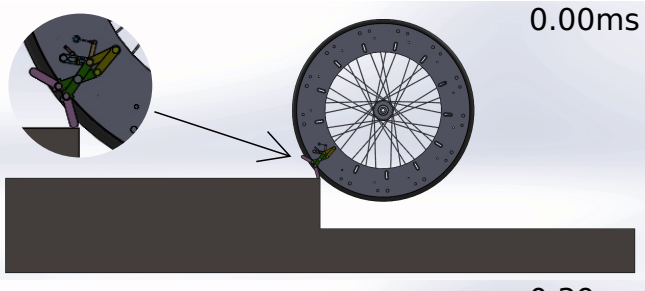

c)

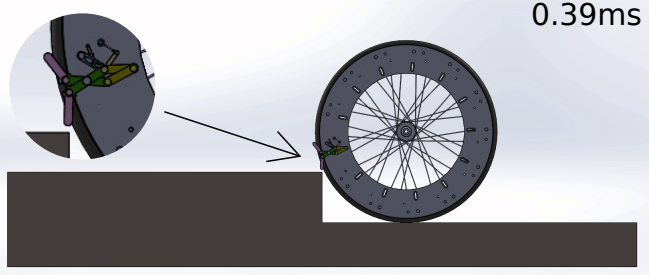

b)

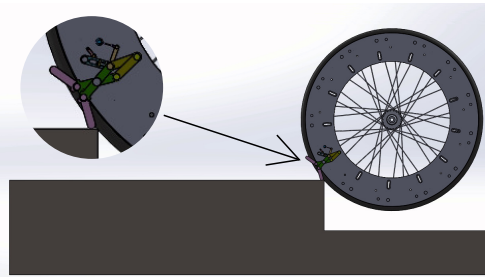

d)

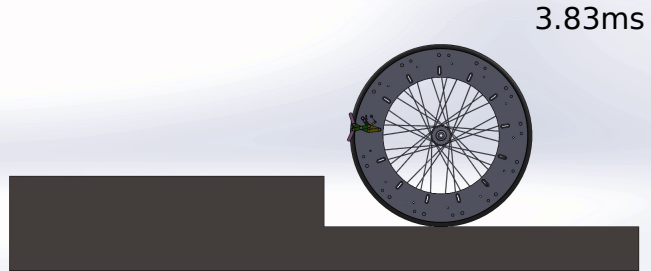

$0.24 \mathrm{~ms}$

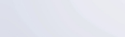

Figure 21. Motion simulation of the mechanism while descending a step (time stamp in milliseconds is roughly estimated from videos) (a) the wheel starts to roll with tip of link 2 as a pivot; (b) as the wheel rolls down, the tip of link 2 touches the edge of the step preventing the wheel from slipping; (c) descending of wheel is complete; (d) wheel moves forward in plane after completion of descending. 


\section{Conclusions}

In this article, an anti-slip mechanism for the wheels of step climbing robots is designed. An array of proposed mechanisms is attached to the wheels of the robot to eliminate the possibility of slipping while maneuvering on stairs. The mechanism enables the robot to clamp on the edges of stairs to prevent the slipping while climbing stairs. This will make it capable of providing efficient and safe climbing operations. Furthermore, using the relationships obtained for the proposed mechanism, a 3D model of the mechanism is developed for a wheel of diameter $580 \mathrm{~mm}$. The performance of the model is found to be satisfactory and verified through Von-Mises stress and deflection analysis under an applied load up to $250 \mathrm{~N}$. The factor of safety in the stress analysis of the mechanism is found to be 3.025. The proposed mechanism may be attached to the wheels of wheel-based robots. This will reduce the risk of the slipping of wheels on the edges of a stair, which in turn improves the climbing capabilities of the robot on the stairs. Such robots may be used for the door-to-door delivery robots, where robots need to climb up/down the stairs of a building to deliver goods at the door. Another application of such a system is to use it in exploration or rescue robots where human deployment is a risky operation. In the future, optimization analysis may be performed to optimize various link parameters. A prototype will be developed and experiments will be carried out to ensure the safe operation of a step climbing robot while climbing up or down the stairs.

Author Contributions: Conceptualization, N.J.B. and H.O.; methodology, N.J.B.; formal analysis, N.J.B. and B.B.; investigation, K.T.; resources, K.T.; writing—original draft preparation, N.J.B.; writing-review and editing, B.B.; visualization, K.T.; supervision, H.O.; project administration, H.O. All authors have read and agreed to the published version of the manuscript.

Funding: This research received no external funding.

Conflicts of Interest: The authors declare no conflict of interest.

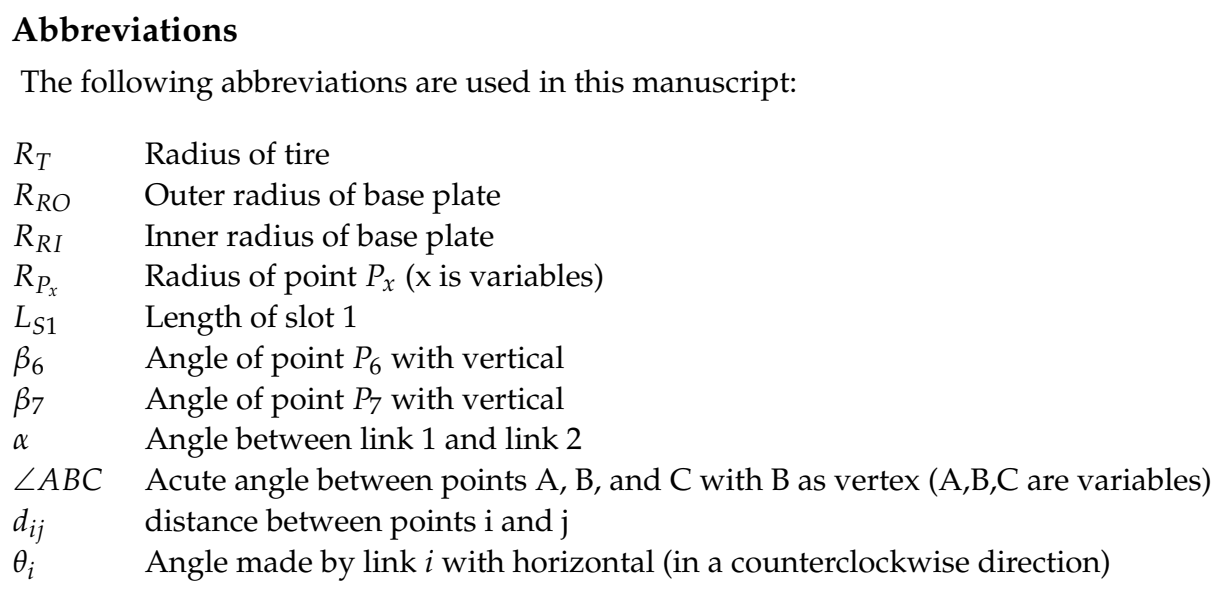

\section{References}

1. Lawn, M.J.; Sakai, T.; Kuroiwa, M.; Ishimatsu, T. Development and practical application of a stairclimbing wheelchair in Nagasaki. Int. Hum.-Friendly Welf. Robot. Syst. 2001, 2, 33-39.

2. Hirose, S.; Fukushima, E.F.; Damoto, R.; Nakamoto, H. Design of terrain adaptive versatile crawler vehicle HELIOS-VI. In Proceedings of the 2001 IEEE/RSJ International Conference on Intelligent Robots and Systems, Maui, HI, USA, 29 October-3 November 2001; Volume 3, pp. 1540-1545. [CrossRef]

3. Yu, S.; Wang, T.; Li, X.; Yao, C.; Wang, Z.; Zhi, D. Configuration and tip-over stability analysis for stair-climbing of a new-style wheelchair robot. In Proceedings of the 2010 IEEE International Conference on Mechatronics and Automation, ICMA 2010, Xi'an, China, 4-7 August 2010; pp. 1387-1392. [CrossRef]

4. Sugahara, Y.; Ohta, A.; Hashimoto, K.; Sunazuka, H.; Kawase, M.; Tanaka, C.; Lim, H.O.; Takanishi, A. Walking up and down stairs carrying a human by a biped locomotor with parallel mechanism. In Proceedings of the 2005 IEEE/RSJ International Conference on Intelligent Robots and Systems, Edmonton, AB, Canada, 2-6 August 2005; pp. 1489-1494.

5. Yuan, J.; Hirose, S. Research on leg-wheel hybrid stair-climbing robot, Zero Carrier. In Proceedings of the 2004 IEEE International Conference on Robotics and Biomimetics, Shenyang, China, 22-26 August 2004; pp. 654-659. [CrossRef] 
6. $\quad$ Bang, Y.B.; Lee, C.H.; Yoo, J.H.; Lee, K.M.; Kim, I.S. Two-legged stair-climbing wheelchair and its stair dimension measurement using distance sensors. In Proceedings of the 2011 11th International Conference on Control, Automation and Systems, Gyeonggi-do, Korea, 26-29 October 2011; pp. 1788-1791.

7. Wang, H.; He, L.; Li, Q.; Zhang, W.; Zhang, D.; Xu, P. Research on a kind of leg-wheel stair-climbing wheelchair. In Proceedings of the 2014 IEEE International Conference on Mechatronics and Automation, Tianjin, China, 3-6 August 2014; pp. 2101-2105. [CrossRef]

8. Meghdari, A.; Pishkenari, H.N.; Gaskarimahalle, A.; Mahboobi, S.; Karimi, R. A novel approach for optimal design of a rover mechanism. J. Intell. Robot. Syst. 2005, 44, 291-312. [CrossRef]

9. Chocoteco, J.; Morales, R.; Feliu, V.; Sanchez, L. Trajectory Planning for a Stair-Climbing Mobility System Using Laser Distance Sensors. IEEE Syst. J. 2016, 10, 944-956. [CrossRef]

10. Woo, C.K.; Do Choi, H.; Yoon, S.; Kim, S.H.; Kwak, Y.K. Optimal design of a new wheeled mobile robot based on a kinetic analysis of the stair climbing states. J. Intell. Robot. Syst. 2007, 49, 325-354. [CrossRef]

11. Zúñiga-Avilés, L.; Pedraza-Ortega, J.; Gorrostieta-Hurtado, E.; Tovar-Arriaga, S.; Ramos-Arreguín, J.; Aceves-Fernández, M.A.; Vargas-Soto, J. HTG-Based Kinematic Modeling for Positioning of a Multi-Articulated Wheeled Mobile Manipulator. J. Intell. Robot. Syst. 2014, 76, 267-282. [CrossRef]

12. Bruzzone, L.; Fanghella, P. Functional redesign of Mantis 2.0, a hybrid leg-wheel robot for surveillance and inspection. J. Intell. Robot. Syst. 2016, 81, 215-230. [CrossRef]

13. Zhu, Y.; Fei, Y.; Xu, H. Stability analysis of a wheel-track-leg hybrid Mobile robot. J. Intell. Robot. Syst. 2018, 91, 515-528. [CrossRef]

14. Qiao, G.; Song, G.; Zhang, Y.; Zhang, J.; Li, Z. A wheel-legged robot with active waist joint: Design, analysis, and experimental results. J. Intell. Robot. Syst. 2016, 83, 485-502. [CrossRef]

15. Bruzzone, L.; Baggetta, M.; Nodehi, S.E.; Bilancia, P.; Fanghella, P. Functional Design of a Hybrid Leg-Wheel-Track Ground Mobile Robot. Machines 2021, 9, 10. [CrossRef]

16. Zhao, J.; Han, T.; Wang, S.; Liu, C.; Fang, J.; Liu, S. Design and Research of All-Terrain Wheel-Legged Robot. Sensors 2021, 21, 5367. [CrossRef]

17. Misawa, R. Stair-Climbing Wheelchair Carrier; ScienceON: Yorba Linda, CA, USA, 1986.

18. Lawn, M.J.; Ishimatsu, T. Modeling of a stair-climbing wheelchair mechanism with high single-step capability. IEEE Trans. Neural Syst. Rehabil. Eng. 2003, 11, 323-332. [CrossRef] [PubMed]

19. Liu, J.; Wu, Y.; Guo, J.; Chen, Q. High-Order Sliding Mode-Based Synchronous Control of a Novel Stair-Climbing Wheelchair Robot. J. Control Sci. Eng. 2015, 2015, 46. [CrossRef]

20. Morales, R.; Feliu, V.; Gonzalez, A.; Pintado, P. Kinematic Model of a New Staircase Climbing Wheelchair and its Experimental Validation. Int. J. Robot. Res. 2006, 25, 825-841. [CrossRef]

21. Morales, R.; Feliu, V.; Gonzalez, A.; Pintado, P. Coordinated motion of a new staircase climbing wheelchair with increased passenger comfort. In Proceedings of the Proceedings 2006 IEEE International Conference on Robotics and Automation, Orlando, FL, USA, 15-19 May 2006; Volume 2006, pp. 3995-4001. [CrossRef]

22. Morales, R.; Gonzalez, A.; Feliu, V.; Pintado, P. Environment adaptation of a new staircase-climbing wheelchair. Auton. Robot. 2007, 23, 275-292. [CrossRef]

23. Gonzalez, A.; Ottaviano, E.; Ceccarelli, M. On the kinematic functionality of a four-bar based mechanism for guiding wheels in climbing steps and obstacles. Mech. Mach. Theory 2009, 44, 1507-1523. [CrossRef]

24. Morales, R.; Feliu, V.; González, A. Optimized obstacle avoidance trajectory generation for a reconfigurable staircase climbing wheelchair. Robot. Auton. Syst. 2010, 58, 97-114. [CrossRef]

25. Shino, M.; Tomokuni, N.; Murata, G.; Segawa, M. Wheeled inverted pendulum type robotic wheelchair with integrated control of seat slider and rotary link between wheels for climbing stairs. In Proceedings of the 2014 IEEE International Workshop on Advanced Robotics and its Social Impacts, Evanston, IL, USA, 11-13 September 2014; pp. 121-126. [CrossRef]

26. Ghani, N.M.A.; Nasir, A.N.K.; Tokhi, M.O. Optimization of fuzzy logic scaling parameters with spiral dynamic algorithm in controlling a stair climbing wheelchair: Ascending task. In Proceedings of the 2014 19th International Conference on Methods and Models in Automation and Robotics (MMAR), Miedzyzdroje, Poland, 2-5 September 2014; pp. 776-781. [CrossRef]

27. Quaglia, G.; Maffiodo, D.; Franco, W.; Appendino, S.; Oderio, R. The Epi.q-1 Hybrid Mobile Robot. Int. J. Robot. Res. 2009, 29, 81-91. [CrossRef]

28. Quaglia, G.; Franco, W.; Oderio, R. Wheelchair.q, a mechanical concept for a stair climbing wheelchair. In Proceedings of the 2009 IEEE International Conference on Robotics and Biomimetics (ROBIO), Guilin, China, 19-23 December 2009; pp. 800-805. [CrossRef]

29. Quaglia, G.; Franco, W.; Oderio, R. Wheelchair.q, a motorized wheelchair with stair climbing ability. Mech. Mach. Theory 2011, 46, 1601-1609. [CrossRef]

30. Quaglia, G.; Oderio, R.; Bruzzone, L.; Razzoli, R. A modular approach for a family of ground mobile robots. Int. J. Adv. Robot. Syst. 2013, 10. [CrossRef]

31. Quaglia, G.; Nisi, M. Design of a Reconfiguration Mechanism for an Electric Stair-Climbing Wheelchair. In Proceedings of the ASME 2014 International Mechanical Engineering Congress and Exposition, Montreal, QC, Canada, 14-20 November 2014; pp. 1-10. 
32. Quaglia, G.; Matteo, N. Design and Construction of a New Version of the EPI.Q UGV for Monitoring and Surveillance Tasks. In Proceedings of the ASME 2015 International Mechanical Engineering Congress and Exposition, Houston, TX, USA, 13-19 November 2015; pp. 1-8.

33. Quaglia, G.; Franco, W.; Nisi, M. Evolution of Wheelchair.q, a Stair-climbing Wheelchair. In Proceedings of the 14th IFToMM World Congress, Taipei, Taiwan, 25-30 October 2015. [CrossRef]

34. Quaglia, G.; Nisi, M. Design of a self-leveling cam mechanism for a stair climbing wheelchair. Mech. Mach. Theory 2017, 112, 84-104. [CrossRef]

35. Chen, C.T.; Pham, H.V. Design and fabrication of a statically stable stair-climbing robotic wheelchair. Ind. Robot 2009, 36, 562-569. [CrossRef]

36. Sugahara, Y.; Yonezawa, N.; Kosuge, K. A novel stair-climbing wheelchair with transformable wheeled four-bar linkages. In Proceedings of the IEEE/RSJ 2010 International Conference on Intelligent Robots and Systems, IROS 2010-Conference Proceedings, Taipei, Taiwan, 18-22 October 2010; pp. 3333-3339. [CrossRef]

37. Baishya, N.J.; Ogai, H. Wa-Chair: A concept for development of economical stair-climbing wheelchair. In Proceedings of the IOP Conference Series: Materials Science and Engineering, Jakarta, Indonesia, 22-23 November 2018; Volume 307, p. 012010.

38. Baishya, N.J.; Ogai, H.; Bhattacharya, B. Design and Development of a New Active Slider Crank Mechanism Based Step Climbing Wheelchair. In Proceedings of the 2019 12th Asian Control Conference (ASCC), Fukuoka, Japan, 9-12 June 2019; pp. $271-276$.

39. Baishya, N.J.; Bhattacharya, B.; Ogai, H.; Tatsumi, K. Analysis and Design of a Minimalist Step Climbing Robot. Appl. Sci. 2021, 11, 7044. [CrossRef]

40. Mavanthoor, A.; Midha, A. Bistable Compliant Four-Bar Mechanisms With a Single Torsional Spring. In Proceedings of the International Design Engineering Technical Conferences and Computers and Information in Engineering Conference, Philadelphia, PA, USA, 10-13 September 2006; Volume 2; pp. 151-157. [CrossRef]

41. Tideman, H. Mechanism of the Lazy-Tong Genus. U.S. Patent 899,769, 29 September 1908.

42. Kalra, S.; Bhattacharya, B.; Munjal, B. Design of shape memory alloy actuated intelligent parabolic antenna for space applications. Smart Mater. Struct. 2017, 26, 095015. [CrossRef] 